\title{
FATORES QUE AFETAM A DETERMINAÇÃO DO FÓSFORO ISOTOPICAMENTE TROCÁVEL EM SOLOS
}

\author{
LUIS EDUARDO MORALES MORALES \\ Engenheiro Agrônomo \\ Instituto de Assuntos Nucleares (Colômbia)
}

Orientador: Prof. Dr. ANDRE MARTIN LOUIS NEPTUNE

Dissertação apresentada à Escola Superior de Agricultura "Luiz de Queiroz", da Universidade de São Paulo, para obtenção do título de Mestre em Energia Nuclear na Agricultura.

\footnotetext{
PIRACICABA

Estado de São Paulo - Brasil Junho, 1981
} 


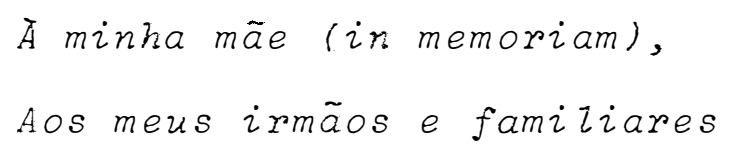

OEERECO.

\author{
A minha esposa \\ e meus filhos
}

DEDICO. 


\section{AGRADECIMENTOS}

Expresso minha sincera gratidāo àsinstituiçōes ou pessoas que, direta ou indiretamente, colaboraram para a realização deste trabalho, em especial as relacionadas a seguir:

- Instituto de Asuntos Nucleares (Colómbia), Agência Internacional de Energia Atōmica, Comissão de Energia Nuclear, Centro de Energia Nuclear na Agricultura (CENA) e Escola Su perior de Agricultura "Luiz de Queiroz", que possibilitaram minha participação no curso de pōs-graduação.

- Aos Drs. Ernesto Villarreal Silva e Jaime Torogutierrez, di retor e subdiretor técnico do Instituto de Asuntos Nucleares respectivamente, pelo apoio e incentivo.

- Ao Prof. André Martin Louis Neptune pela sugestão do assunto e segura orientação desta pesquisa.

- Ao Dr. Takashi Muraoka pela constante colaboração, incentivo e amizade.

- Aos Profs. Drs. Klaus Reichardt, Paulo Libardi e Virgiliof. Nascimento, pelo apoio e incentivo concedidos durante meu e tāgio no CENA.

- Ao Eng. Agr. Gonzalo Bastidas pelo auxilio na instalação, condução, análise dos experimentos e sugestões apresentadas.

- Ao Dr. Peter Vose da Agência Internacional de Energia Atómica. 
- Ao Dr. Marco A. Perdomo C. pelo apoio e amizade.

- Ao Dr. Ricardo B. Sgrillo responsāvel pela divisão de ensino e extensão, pela colaboração e amizade.

- Aos Engs. Agrs. Pablo Guzman e Jairo Jimenez pelo auxilio e sugestões apresentadas.

- Aos Drs. Carlos C. Cerri e Reinaldo Victoria pelo apoio e amizade.

- Ao Sr. José Osório da Seção de Dosimetria e proteção radioló gica do CENA.

- As srtas. Marileusa A. Bassi, Sandra Teresa Pereira, Silvia R.C. Prates e Sandra Maria G. Nicoletti da Seção de Fertili dade do Solo.

- Aos Srs. João 0. Salvador, Rudinei Romani, Anderson Forti e Dacir Bartoleto da Seção de Fertilidade do Solo.

- A sra. Janeti L.B. de Moura e äs srtas. Rosa Maria V.B. 01 i veira, Pedrila de Fatima Pellegreinotti e Marcia A. Leiteda biblioteca do CENA.

- Aos srs. Luis C. Veríssimo, Eurice A. Mello e Moacir P. de Oliveira da biblioteca da ESALQ.

- A sra. Diva Athié da Agéncia Internacional de Energia Atómica.

- Aos srs. Ariovaldo M. Carvalho e Francisco C. Pellegrino do Centro de Processamento de Dados do CENA.

- Aosr. Jorge Luiz Diorio, pelo trabalho datilogräfico. 
LISTA DE FIGURAS ....................

RESUMO $\ldots \ldots \ldots \ldots \ldots \ldots \ldots \ldots \ldots \ldots \ldots \ldots \ldots \ldots \ldots \ldots \ldots \ldots \ldots \ldots$

SUMMARY $\ldots \ldots \ldots \ldots \ldots \ldots \ldots \ldots \ldots \ldots \ldots \ldots \ldots \ldots \ldots \ldots \ldots \ldots$

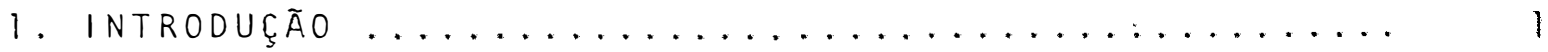

2. REVISÃo de literatura $\ldots \ldots \ldots \ldots \ldots \ldots \ldots \ldots \ldots \ldots \ldots$

2.1. Principios e equações .................... 3

2.2. Fatores que afetam a determinação do fösforo iso topicamente trocàvel ................. 8

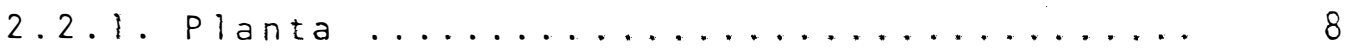

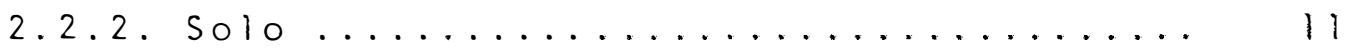

2.2.3. outros fatores ................. 12

3. MATERIAIS E METODOS ...................... 16

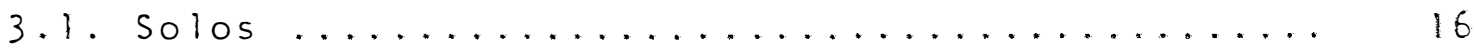

3.2 . Adubos ........................... 18

3.3. Metodologia $\ldots \ldots \ldots \ldots \ldots \ldots \ldots \ldots \ldots \ldots \ldots \ldots$

3.3 .1 . Primeiro ensaio ................. 18

3.3.1.1. Delineamento experimental .... 18

3.3 .1 .2$. Tratamentos ............. ig

3.3 .1 .3$. Procedimento ........... ig 
3.3.2. Segundo ensaio .......................... 21

3.3.2.1. Delineamento experimental .... 21

3.3.2.2. Tratamentos ............. 21

3.3 .2 .3 . Procedimento ............ 22

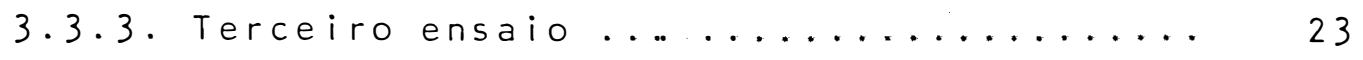

3.3.3.1. Delineamento experimental .... 23

3.3 .3 .2 . Procedimento ............. 23

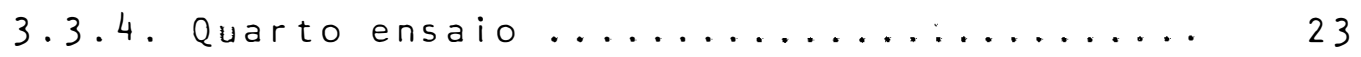

3.3.4.1. Delineamento experimental ... 23

3.3 .4 .2 . Tratamentos ............... 24

3.3 .4 .3 . Procedimento ............ 24

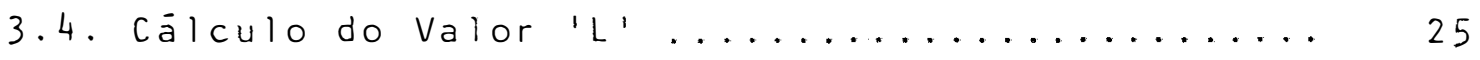

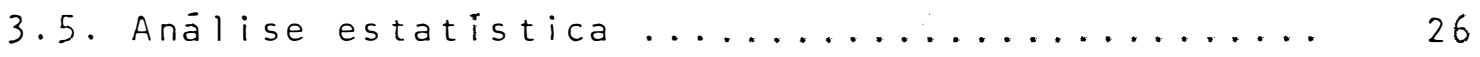

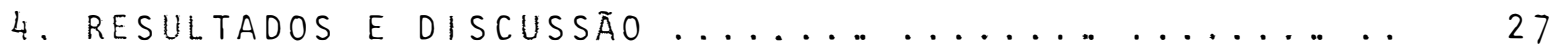

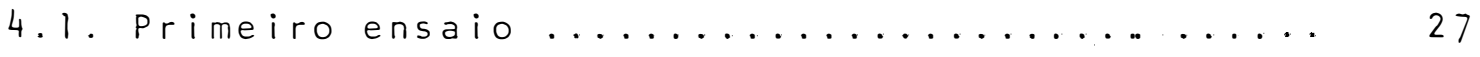

4.1.1. No solo podzölico (PVA) ............. 27

4.1.2. No latossolo (LE) ............... 33

4.2. Segundo ensaio ....................... 37

4.2.1. No solo podzölico ................ 37

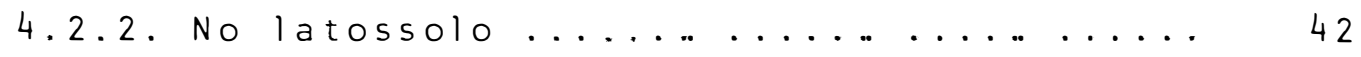

4.3. Terceiro ensaio ...................... 45

4.4. Quarto ensaio ........................ 47 
vi i .

Pàgina

4.4.1. Efeito dos niveis de $P$ nas duas culturas

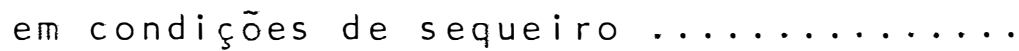

4.4.2. Efeito dos niveis de P no arroz cultiva-

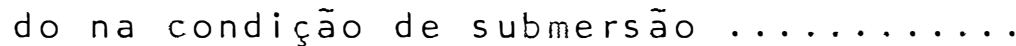

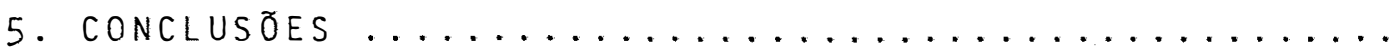

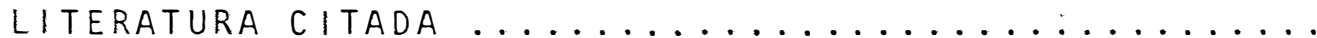




\section{LISTA DE TABELAS}

TABELA 1. Características químicas, físicas e mineralógicas dos solos estudados $\ldots \ldots \ldots \ldots \ldots \ldots \ldots$

TABEla 2. Ensaio 1. Quantidade de Material Vegetal seco (MVS), porcentagem de fósforo (\%P), fósforoto tal, atividade especifica (sp) e valor 'L' dos tratamentos no solo podzolizado ..........

TABELA 3. Ensaio 1. Quantidade de Material Vegetal seco (MVS), porcentagem de fósforo (\%P), fósforoto tal, atividade especifica (sp) e valor 'L' dos

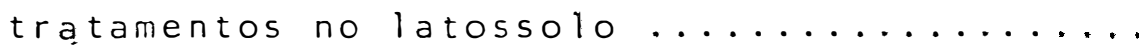

TABELA 4. Ensaio 2. Quantidade de Material Vegetal seco (MVS), porcentagem de fósforo (\%P), fósfo rototal, atividade específica (sp) e valor 'L' dos tratamentos no solo podzolizado.....

TABELA 5. Ensaio 2. Quantidade de Material Vegetal seco (MVS), porcentagem de fösforo (\%P), fósforo to tal, atividade especifica (sp) e valor 'L'dos

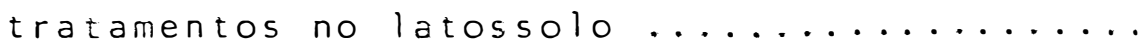


TABELA 6. Ensaio 3. Quantidade de Material Vegetal seco (MVS), porcentagem de fósforo (\%P), fósforo to tal, atividade especifica (sp) evalor 'L' dos

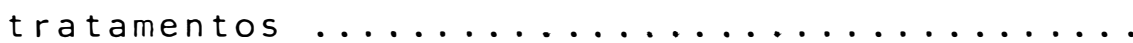

TABELA 7. Ensaio 4. Quantidade de Material Vegetal seco (MVS), porcentagem de fösforo (\%P), fösforo to tal, atividade especifica (sp) evalor 'L' dos

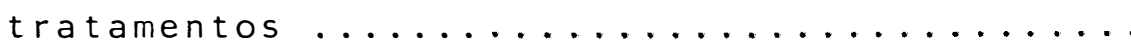

TABELA 8. Ensaio 4. Quantidade de Material Vegetal seco (MVS), porcentagem de fösforo (\%P), fösforo to tal, atividade especifica (sp) evalor 'L' dos

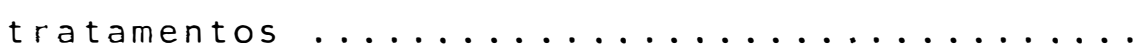




\section{LISTA DE FIGURAS}

FIGURA I. Distribuição dos vasos na casa de vegetação:

a) primeiro ensaio, colheita aos 50 dias; b)

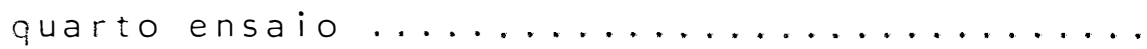

FIGURA 2. Valor 'L' em função dos niveis do carregador: a) no solo podzólico; b) no latossolo.......

FIGURA 3. Valor 'L' em função dos niveis de carregador: a) no solo podzólico; b) no latossolo.......

FIGURA 4. Valor ' $L$ ' em função dos niveis de carregador: solo podzolizado.

FIGURA 5. Valor 'L' em função dos niveis de carregador: a) nas duas culturas; b) nas duas condições de

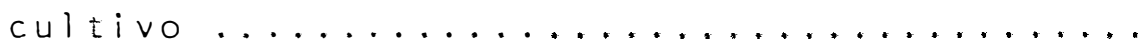


RESUMO

\section{FATORES QUE AFETAM A DETERMINAÇÃO DO FOSFORO ISOTOPICAMENTE TROCAVEL EM SOLOS}

Luis Eduardo Morales Morales Andrē Martin Louis Neptune

Para avaliar os fatores que afetam a determina ção do fósforo isotopicamente trocável em solos (Valor 'L'), realizaram-se diversos ensaios em casa de vegetação. Foram con siderados os seguintes fatores: niveis de carregador $(0,1$ $1,3-5-10-11-22-33-66-99$ e 220 ppm de fósforo), espécie vegetal (arroz e feijoeiro), épocas de colheital 30 e 50 dias), doses de nitrogēnio $(50$ e $100 \mathrm{~kg} \mathrm{~N} / \mathrm{ha})$, fontes de ni trogénio (uréia e sulfato de amōnio), condições decultivo (se queiro e submersão) e tipo de solo (Podzólico vermelho amarelo equivalente eutrófico e Latossol vermelho escuro). Uma solução radioativa com uma atividade apro-

ximada de 10 HCi $32 \mathrm{p} / 3 \mathrm{~kg}$ de solo, com diversos niveis de car regador segundo o tratamento, foi colocada em camadas ou misturada completamente com o solo segundo o ensaio. Dos resulta dos obtidos, foram tiradas as seguintes conclusões:

1. Os valores ' $L$ ' foram mais altos quando foram utilizadosbai xos niveis de carregador nos dois solos. 
2. Os valores ' $L$ ' dependem da espécie vegetal. Foram maiores para o feijoeiro do que para o arroz.

3. Os valores 'L' no latossolo variaram com a época de colhe ta.

4. A dose e fonte de nitrogènio não afetaram os valores 'L'. Porém, o sulfato de amónio causou um efeito sinérgico na absorção de $P$ quando a dose de carregador foi de 220 ppm no solo podzolizado.

5. No latossolo, a condição de submersão aumentou a produção de material vegetal seco e o teor de fósforototal, porém, os valores ' $L$ ' permaneceram constantes.

6. Os valores 'L' obtidos com niveis de carregador de 1,3 a 11 ppm de $P$, com arroz aos 30 dias, foram semelhantes aos obt dos com $\mathrm{H}_{2} \mathrm{SO}_{4} 0.05 \mathrm{~N}$ no solo podzolizado. No latossolo foram completamente diferentes. 
SUMMARY

\section{FACTORS AFFECTING THE DETERMINATION OF THE ISOTOPICALLY EXCHANGEABLE PHOSPHORUS IN SOILS.}

Luis Eduardo Morales Morales André Martin Louis Neptune

In order to evaluate the factors that affect the determination of the isotopically exchangeable phosphorus in soils ('L' value), various greenhouse experiments werecarried out. The following factors were considered: carrier level $(0.1-1.3-5-10-11-22-33-66-99$ and 220 ppm phosphorus); plant species (rice - Oryza sativa, L. and bean - Phă seolus vulgaris, L.); harvest time (30 and 50 days); nitrogen doses (50 and $100 \mathrm{~kg} \mathrm{~N} / \mathrm{ha}$ ); nitrogen sources (urea and ammonium sulfate); culture conditions (upland and flooded conditions) and soil type (red-yellow podzolic and dark red Latos sol).

A radioactive solution with an activity level of approximately $10 \mu \mathrm{Ci} 32 \mathrm{p} / 3 \mathrm{~kg}$ soil with different carrier levels was located in layers or mixed completely with the soil depending upon the experiment. The results obtained allowedus to draw the following conclusions:

1. The 'L' values were higher when low carrier levels were used in both soils. 
$x i v$.

2. The ' $L$ ' values were dependent upon the plant species. They were higher with beans than with rice.

3. The 'L'values in the latossol varieddepending upon the harvest time.

4. Neither the nitrogen dose nor the nitrogen source affected the 'L' values. Nevertheless, ammonium sulfate caused a sinergic effect upon the $P$ uptake when the carrier dose was 220 ppm in the podzolic soil.

5. In the latossol, flooded conditions increased the dry matter production and the total phosphorus level, however the 'L' values remained constant.

6. The ' $L$ ' values obtained in rice of 30 days with carrier le vels from 1.3 to 11 ppm $P$ were similar to those obtained in the Podzolic soil with $\mathrm{H}_{2} \mathrm{SO}_{4} 0.05 \mathrm{~N}$. In the latossol, they were completely different. 


\section{INTRODUÇÃO}

A possibilidade de desenvolver técnicas mais exatas na pesquisa em Fertilidade do Solo pelo uso dos isótopos radioativos dos elementos nutritivos da planta foi reconhecida e demonstrada por STOUT e HOAGLAND, 1939, porém, foi so mente a partir de 1946 que surgiu a oportunidade de analisar cuidadosamente esta nova e promissória ferramenta (ENSMINGER e PEARSON, 1957).

A mudança na atividade especifica do nutriente aplicado como resultado da diluiçāo isotópica na planta ou no solo é a base dos experimentos realizados em laboratório (valor 'E') e em casa de vegetação (valor 'L') para avaliar o es tado nutricional do solo.

o fósforo isotopicamente trocável do solo (va-

lor 'L') è uma medida quantitativa que representa a quantidade de $P$ disponível para o cultivo sob condições particulares de crescimento (WILLIAMS e KNIGHT, 1963). 
Mas apesar das altas correlações obtidas por inümeros pesquisadores entre o valor 'L' e o fósforo dispon í vel ou 'Pool' de fosfato do solo, esta metodologia, da mesma maneira que os métodos convencionais de anälise, tem sérias limitações (RUSSELL et alii, 1954 e OZBEK e AYDENIZ, 1965).

o objetivo deste trabalho é então avaliar com base nos principios da diluição isotópica, o fósforo isotopí camente trocāvel em dois solos do Estado de São Paulo, usando para este propósito o isótopo radioativo ( 32 p) com diferentes niveis de carregador, espécies de planta, época de colheita, doses e fontes de nitrogènio, e duas condições de cultivo (sub mersão e sequeirol. 


\section{REVISÃO DE LITERATURA}

\subsection{PRINCIPIOS E EQUAÇOES}

\section{Segundo MCAULIFFE et alii (1948), foi Paneth} em 1922 quem fazendo uso dos traçadores isotópicos estudou as reações de troca entre sais de chumbo de uma superficie sölida e uma solução contendo o isótopo radioativo $212 \frac{2}{8 b}$. A reação bàsica è:

$\mathrm{PbSO}_{4}\left(\right.$ sup.sōlida) +Pb*( solução) $\rightleftarrows \mathrm{Pb}^{\star} \mathrm{SO}_{4}(\mathrm{Sup}$. sōlida)+Pb (sol ução)

como a constante de equilibrio é igual a (1), então:

$$
\begin{aligned}
& \frac{P b^{\star}(\text { superficie })}{P b^{\star}(\text { solução) }}=\frac{P b \text { (superficie) }}{P b \quad \text { (solução) }} \\
& \text { Este principio pode ser aplicado a reações no }
\end{aligned}
$$
solo que envolvem fósforo

$$
31 p(\text { superficie })+32 p(\text { sol. })+32 p(\text { superficie })+31 p(\text { sol })
$$


Assumindo que em equilibrio a relação,dos dois isōtopos na fase sōlida é igual a sua relação na fase líquida (SPINKS e BARBER, 1947), o 31 p na fase sölidapode ser calculä do da seguinte maneira:

$$
\begin{aligned}
& \frac{32 p(\text { sup })}{32 p(\text { sol })}=\frac{31 p(\text { sup })}{31(\text { sol })} \text { ou } 31 p(\text { sup })=\frac{32 p(\text { sup })}{32 p(\text { sol })} \times 31 p(\text { sol. }) \\
& \text { o termo } 31 p \text { (sup.) tem sido chamado frequente- }
\end{aligned}
$$
mente como fósforo de superficie (McAULIFFE et alii, 1948), ou fosfato isotopicamente trocāvel na fase sólida (ULRICH, etalii $1962)$.

Hevesy, 1923 citado por LARSEN (1952) introduziu o uso de isótopos radioativos na pesquisa de fisiologiade plantas e animais. O mesmo autor em 1936 iniciou os estudos so bre absorção de fósforo pelas plantas utilizando o isótopo $32 p$, obtido pela irradiação de $3 l_{p}$ com neutrons de uma fonte de radio-berilio (MATTINGLY, 1957).

Segundo NEPTUNE e MURAOKA (1978) a lei de diluição isotōpica de Hevesy afirma que em condiçōes de equilíbrio isotópico, a atividade ou a percentagem de àtomos de isótopos estāveis è constante através do sistema. Para HENDRICKS e DEAN (1948), a mudança na atividade específica que resulta da diluição è a base da maioria de experimentos com fertilizantes.

Se um adubo marcado é adicionado a um solo sobre o qual uma cultura está crescendo, a radioatividade de uma 
quantidade unitária de fosfato encontrada nas plantas, indicará a quantidade de fosfato derivado do fertilizante (HENDRICKS e DEAN, 1948). A determinação deste fósforo pela diluição com fosfato radioativo se chama diluição isotópica direta (MEKHAEL et alii, 1965) e segundo CHASE e RABINOWITS (1967) podeser re presentada por:

SOLUÇÃO ESTOQUE MARCADA

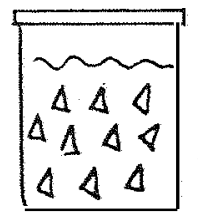

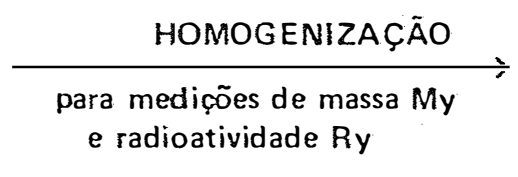

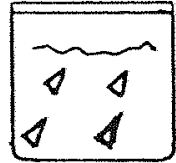

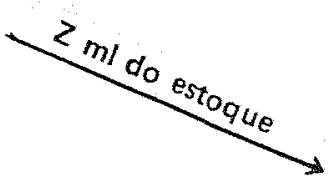

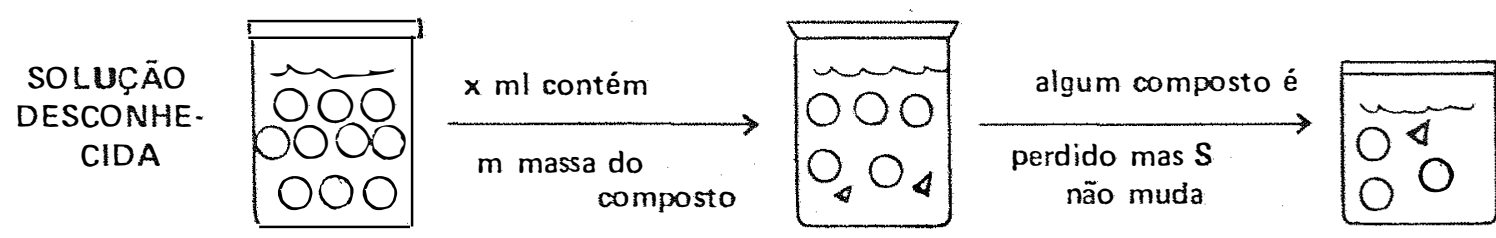

$$
\begin{array}{ll}
\text { At ividade }=R^{\prime} & \operatorname{Rr} \text { é a atividade da massa } \\
\text { Massa do composto }=m+m^{\prime} & \text { Mr recuperada } \\
S=\frac{R}{m+m^{\prime}} & S=\frac{R r}{m r}
\end{array}
$$

Se: $R^{\prime}=$ atividade $(c / m i n)$ da amostra no estoque utilizado

$m^{\prime}=$ massa da amostra estoque

$m=$ massa da substāncia inativa desconhecida usada então a atividade especifica $S^{\prime}$ do padrão é:

$S^{\prime}=\frac{R^{\prime}}{m^{\prime}}(1)$

e a atividade especifica da substáncia isolada emfor ma pura da mistura é: 


$$
S=\frac{R^{\prime}}{m^{\prime}+m}=\frac{R r}{m r}
$$

Então dividindo a equação (1) pela equação (2) fica:

$\frac{S^{\prime}}{S}=\frac{R^{\prime} / m^{\prime}}{R^{\prime} /\left(m^{\prime}+m\right)}=\frac{m^{\prime}+m}{m^{\prime}}=1+\frac{m}{m^{\prime}}$ ou $\frac{m}{m^{\prime}}=\frac{S^{\prime}}{S}-1$

e $m=m^{\prime}\left(\frac{S^{\prime}}{s}-1\right)$

(3) é a mesma equação que utilizou LARSEN (1952) para estimar ovalor 'L', mas ele a representou

$$
Y=\left(\frac{C_{0}}{C}-1\right) \times
$$

onde: $\quad Y=$ quantidade de fósforo trocável presente no solo

$$
\begin{aligned}
C_{0} & =\text { conteúdo de radiofósforo de } \times(32 p) \\
c & =\text { quantidade de radiofósforo absorvido pela planta } \\
X & =\text { quantidade de fósforo adicionado }
\end{aligned}
$$

RUSSELL et alii (1957) a modificaram, ficando:

$$
L=\frac{Y_{f}\left(X_{p}-D\right)}{Y_{P}}-X_{f}
$$

onde: Yf e Yp = radioatividade do adubo e da planta respectivamente $X_{f}$ e $X_{p}=$ fósforo-32 (radioatividade) e fósforo total na planta respectivamente D = conteūdo de fósforo da semente

Na equação (5) considerando D igual a zero lou descontando previamentel e o nivel de carregador muito baixo, tendendo a zero obtēm-se: 


$$
L=\frac{Y_{f} \cdot X_{p}}{Y_{p}}=\frac{X_{p} \times 100}{Y_{p} / Y_{f \times 100}}
$$

e fazendo-se $X_{p}=P$ e $\quad \underline{Y p} \times 100=K$

$$
\text { tem-se } L=' x^{\prime}=\frac{P \times 100}{K}
$$

onde: ' $x^{\prime}=$ quantidade de fosfatos assimiláveis do solo

$$
\begin{aligned}
P= & \text { quantidade de } 31 P \text { absorvido pelas plantas } \\
K= & \text { porcentagem de } 32 p \text { absorvido pelas plantas ou } \\
& \text { "coeficiente de utilização". }
\end{aligned}
$$

A equação (6) è a expressão usada por sokoloV (1955, 1958) para calcular o fósforo disponivel do solo.

A equação de Sokolov reduz-se à de Larsen, quando a dose do carregador é suficientemente baixa, porque todo - 31 p absorvido vem do nativo do solo (VOLK e MCLEAN, 1963).

Para o propósito agronômico de comparar o esta do relativo do fósforo nos solos os valores 'E' e 'L' são suficientemente semelhantes para apreciá-los como medidas alter nativas aos processos quimicos convencionais (RUSSELL, et alii, 1957). Também o método pode ser utilizado para comparar diferentes adubos fosfatados aplicados somente a um solo. 0 valor 'E' ē obtido pela agitação do solo como uma solução de P marcado; a quantidade de fosfato trocável no solo é calculada pe las mudanças na atividade especifica da solução. Para estimar o valor 'L' o nutriente marcado é adicionado ao solo e permite-se que as plantas se desenvolvam. 
RUSSELL et alii (1957) modificaram o método de Larsen e mostraram que ' $L$ ' é independente da quantidade docar regador e do tempo da amostragem se o fósforo foi completamen te misturado com o solo. Esse autor concluiu que era melhor utilizar 32 p livre de carregador para prevenir reações químicas entre o carregador e o solo que podem reduzir a diluição isotöpica. Previamente FRIED e DEAN (1952), definiramo valor 'L' como a quantidade de $P$ no solo e na solução do solo que é trocável com íons ortofosfato adicionados ao solo como medida de um sistema com plantas. Esta definição requer equilíbrio isotōpico; se este não for atingido o valor 'L' não è único, e se for pode ser um índice do $P$ disponivel no solo (IAEA, 1976).

\subsection{FATORES QUE AFETAM A DETERMINAÇĀO DO FOSFORO ISOTOPICAMENTE TROCAVEL}

Considera-se que o valor 'L' é afetado por alguns fatores entre os quais destacam-se: a espécie vegetal, as caracteristicas do solo e outros fatores que dependem da meto dologia utilizada.

\section{$2.2 .1 . \overline{p l a n t a}$}

Segundo ANDERSEN e THOMSEN (1979) a eficiência de utilização do P do solo e do fertilizante depende das caracteristicas das plantas. E bem conhecido o fato de que es- 
pécies de plantas e ainda dentro de variedades da mesma espécie, diferem na sua habilidade para absorver $P$ do solo pouco solúvel e na sua resposta à adubação. Isso pode ser devido prin cipalmente à extensão de seu sistema radicular e a diferenças fisiolögicas no mecanismo de absorção de nutrientes. NELSON et alii (1948) relataram diferença na absorção de $P$ por duas culturas em solos com teores similares de $P$ e supuseram que se devia a diferenças na extensão do seu sistema radicular. Resultados semelhantes tem sido citados por outros autores (SCHEFFER e ULRICH, 1958; SCHENK e BARBER, 1979).

\section{Os experimentos realizados por MARAIS e FOURIE}

(1956), com centeio, cevada, tomate e pepino tem mostrado que o valor ' $L$ ' de um solo permanece igual independentemente des tas espécies cultivadas. Outros pesquisadores, porém, tem encontrado valores ' $L$ ' diferentes concluindo que determinadas e pécies de plantas são mais eficientes que as outras na absorção de $P$ do solo de baixo potencial (NYE e FOSTER, 1958; RUSSELL, 1963). PROBERT (1972) obteve valores 'L' mais altos para trevo do que para rye grass no terceiro corte e atribuiu, esse fato, a maior absorção de cālcio por trevo. Resultados se melhantes foram encontrados por OSBEK e AYDENIZ (1967) que re lataram variaçōes dovalor' $A$ '. com o tipo de cultura, com valores altos para milho e baixos para millet.

RUSSELL et alii (1957) consideram que se comete um erro quando não se desconta o fósforo da semente. NYE e FOSTER (1958) encontraram diminuição nos valores 'L' quando o. 
P da semente era uma apreciāvel fração do P absorvido pelas plantas, devido a trocas entre o $P$ da semente e o $32 \mathrm{p}$ adiciona do ao solo. Para LARSEN e COOKE (1961), os valores 'L' baseados nos dois primeiros cortes aos 15 e 31 dias após o plantio, são influenciados pelo $P$ da semente. Em trabalho semelhante PR 0 BERT (1972) notou que os valores ' $L$ ' para trevo eram superestimados no primeiroe segundo cortes pelo P da semente. SPINKS e BARBER (1947) e MALEINA (1958) subtraíram do P total absorvido - P da semente. SCHEFFER e ULRICH (1958) encontraram que mais de $80 \%$ do $P$ da semente se intercambia com o'P marcado de uma solução dentro das primeiras semanas de crescimento. ParanepTUNE (1964), 65\% do $P$ da semente de arroz de transloca para a parte aérea. Segundo RUSSELL (1963) o P da semente pode ser ignorado quando é uma pequena porção do $P$ absorvido.

Quanto à ëpoca de colheita, LARSEN e SUTTON (1963) concluíram que a variação do valor 'L' com o tempo segue um padrão definido: o valor 'L' pode aumentar devido ao $P$ da semente ou pode diminuir devido à que o equilíbrio isotóp í co não tenha sido atingido. ANDERSEN et alii (1961) relataram incrementos substanciais do valor ' $L$ ' através do período de crescimento, porém, MARAIS e FOURIE (1956) e RUSSELL et alii (1958) encontraram valores ' $L$ ' constantes através do tempo; en quanto PROBERT (1972) notou que os valores 'L' aumentavam com o decorrer do experimento e o atribuiu a falta de equilíbrio e mineralização do P orgânico não läbil. Para vose (1980). um experimento de longa duração é desejāvel para permitir que o 
equilíbrio isotōpico seja atingido e os valores 'L' fiquem constantes.

\section{2 .2 . Solo}

Segundo LARSEN (1964) o tamanho do 'pool' de P

lábil do solo é primeiramente determinado pelas propriedades do solo e não pelo teor total de P inorgânico. AMER et alii (1969) encontraram que o P lábil do solo aumentou com o teor de öxidos de ferro. DALAL e HALLSWORTH (1977) encontraram que o valor 'L' se correlacionava significativamente com o cálcio e o magnésio trocáveis, pH do solo, carbono orgânico e ferro do solo. Então o valor 'L' é um parâmetro composto que toma em conta um grande nūmero de características do solo, o que dá a melhor estimativa do P disponível.

MALEINA (.1958) encontrou que quando existe uma grande reserva de $P$ no solo, o grau de utilização do P do adubo é bastante baixo e vice-versa. Para RUSSELL et alii (.1957) a ocorrència de altos valores 'L', em solos nos quais as plantas absorveram relativamente pequenas quantidades de fosfato, é um indício de que o fenōmeno de fixação está presente nos so los. NEPTUNE e CAMPANELL (1961) consideram que em solos bem ricos em $P$, é menor o efeito do $P$ da semente e vice-versa.

$$
\text { LARSEN "e SUTTON (1963), em um experimento para }
$$

analisar o efeito do volume do solo sobre os valores 'L', cons tataram que a absorção de $P$ por quilograma de solo e o valor 
'L' aumentaram com a diminuição do volume de solo. Resultados semelhantes foram obtidos por outros autores (MALEINA, 1958 ; ANDERSEN et alii, 1961 e CARMELLO, 1980), que atribuiram a maior atividade radicular nos vasos pequenos a causa dos valo res 'L' altos. LAMM (1962), porém, encontrou diminuições na atividade especifica do 32 quando reduziu o tamanho do vaso. SHAPIRO e ARMIGER (1958) em um experimento com rochas fosfatadas e $32 p$ em dois solos, concluiram que as con dições de submersão aumentaram o $P$ disponivel dos solos. Resultados semelhantes foram obtidos por LARSEN (1964). OLSEN et ali (1961) consideraram que com maior umidade do solo, mais rápida è a velocidade de difusão dos íons fosfato. PATNAIK et alii (1979) constataram que a absorção do P do adubo foi maior em solos inundados. LARSEN (1969) obteve valores 'L' constantes em condições de inundação, indicando equilíbrio isotópico entre o $P$ adicionado e o $P$ do solo, possivelmente devido a um incremento no P läbil do solo por redução do íonférrico. ABDEL SALAM et alii (.1962) relataram maior absorção de p com aumento de umidade do solo de 11 para $28 \%$.

\subsubsection{0utros fatores}

LARSEN (1952) em seu experimento para determi nar o fósforo trocável-do solo utilizou fosfatos de cálcio de diferentes solubilidades, marcados com 32 . Misturou completa mente com o solo $(25 \mathrm{~kg})$ niveis de $\mathrm{Po}_{4}^{3-}$ de 1 até 8 mmoles/ 
kg de solo e plantou cevada. os cortes em värias épocas até a colheita, mostraram que quando uma fração definida do p do solo toma parte na diluição isotöpica o valor do termo $Y=(C o / C-l) x$ serä independente da quantidade de fosfato adicionado, mas dependente da sua solubilidade.

GUNARY e SUTTON (1967) em um experimento com três níveis de $P(0,500$ e $1000 \mathrm{~kg} / \mathrm{ha}$ aproximadamente $)$ encon traram altas correlações entre os valores 'L' e o nível zero de P, e menores correlaçōes entre valores ' $L$ ' e altas doses de P. Resultados semelhantes foram obtidos por MARAIS e FOURIE (1956) que constataram também que o nivel carregador tem pouca influéncia sobre os valores ' $L$ '. A iguais conclusões chega ram outros autores (GRUNES et alii , 1955; MATTINGLY, 1957; RUS SELL et alii, 1958; ANDERSEN et ali i, 1961 e MARAIS et alii, $1969)$.

Alguns autores, porém, relatam aumentos do valor 'L' com o incremento do nível de carregador (SOKOLOV, 1958; MALEINA, 1958; VOLK e MCLEAN, 1963 e OSBEK e AYDENIZ, 1965). NYE e FOSTER (1958) encontraram que um aumento do nivel decar regador causou uma diminuição nos valores 'L' em aproximadamente 40\%. AMER et ali i (1969) consideram que o método livre de ${ }^{-}$carregador superestima os valores 'L'. Para IAEA (1976) e VOSE (1980) os valores 'L' devem ter pequenas quantidades de carregador (a mínima possivel).

Quanto as formas de aplicação do $P$ aosolo, LAR SEN (1967), considera que em experimentos em vasos o fosfato 
pode ser adicionado igualmente em forma líquida ou sōlida, mi $\underline{s}$ turado ou na superficie ou variando a solubilidade e tamanho das partículas. Para RUSSEl et alii (1958) o fato de não mis turar o $32 p$ completamente com o solo também não explica os diferentes valores 'L' entre espécies. MALEINA (1958) conside ra que $032 p$ deve ser misturado uniformemente com o solo e de ve ser solūvel em ägua. Para MARAls et alii (1969) os valores 'L' contrastantes são causados pelo uso de adubos pulvereos onde é difícil obter uma mistura completa, por isso recomenda a aplicação em forma líquida. CARMELLo (1980) não encontrou di ferença em valores 'L' quando aplicou a solução com 32 em cạ madas ou completamente misturada com o solo.

RUSSELL et alii (1958) observaram que os valores 'L' não são afetados pelo enriquecimento anterior dos solos com P. Para ANDERSEN et alii (1961), o armazenamento afetou os valores 'L' para cevada, trevo vermelho e ryegrass. Um aumento de $60 \%$ foi encontrado para um período de incubação de 81 dias no ryegrass, devido a que ocorreu diluição e algum fosfato adicionado foi convertido em outros compostos demenor so lubilidade. Segundo LARSEN e GUNARY (1964) o pré-tratamentodo solo com fosfato marcado até dois meses antes do plantio, tem pouca influéncia sobre a mudança do valor 'L' com o tempo. Is so quer dizer que o tempo não foi suficiente para atingir o equilíbrio completo. A diluição, então, é acelerada durante o periodo de crescimento e com plantas em desenvolvimento.

Normalmente nos experimentos para determinação 
de valor 'L', a adubação com nitrogênio e potássio é feita, porēm, resultados mostrando efeito do $N$ sobre os valores 'L' tem sido relatados. ESSAFI et ali i (1962) e CALDWELL e BLANCHAR (1965), constataram um aumento na absorção do $P$ do adubo com a aplicação de N como $\mathrm{NH}_{4}$. Rennie (1960) citado por RENNIE e SPRATT (1962) também obtiveram incremento na absorção de P pela adição de $\mathrm{NH}_{4}$, mas não houve efeito do ion $\mathrm{NO}_{3}^{-}$. Para $A N-$ DERSEN et alii (1961), porém, a adição de $N$ não afetou os valores ' $L$ '. 


\title{
3. MATERIAIS E METODOS
}

\begin{abstract}
Foram realizados quatro ensaios, em casa de ve getação em diferentes épocas do ano, no período de setembrol 79 a abril/81.
\end{abstract}

3.1. SOLOS

Utilizaram-se dois tipos de solo: Latossol ver melho escuro (LE) e Podzölico Vermelho Amarelo (PVA) equivalente eutrófico. As suas caracteristicas quimicas, físicas e mineralógicas aparecem na tabela 1 .

$$
\text { Para a análise química visando avaliar a ferti }
$$

lidade dos solos, seguiu-se a metodologia descrita por CATAN I et alii (1955). Na anälise física, seguiu-se o método de pipe ta, descrito por KILMER e ALEXANDER (1949). A classificação textural foi determinada de acordo com o descrito por MEDINA $(1972)$ 
Tabela 1. Características quimicas, físicas e mineralógicas dos solos estudados

a) Anālise química

\begin{tabular}{cccccccc}
\hline & $\mathrm{PH}$ & $\mathrm{C}$ & $\mathrm{PO}_{4}^{3-}$ & $\mathrm{K}^{+} \mathrm{Ca}^{2+}$ & $\mathrm{Mg}^{2+}$ & $\mathrm{Al}^{3+}$ & $\mathrm{H}^{+}$ \\
\cline { 3 - 4 } & $\left(\mathrm{H}_{2} \mathrm{O}\right)$ & $(\%)$ & \multicolumn{3}{l}{ emg/100g terra } \\
\hline
\end{tabular}

PVA

(tropudalf)

$4,8 \quad 0,12 \quad 0,116 \quad 0,19 \quad 1,6 \quad 0,56 \quad 0,16 \quad 2,88$

$\begin{array}{lllllllll}\text { LE } & 5,6 & 1,08 & 0,139 & 0,49 & 5,4 & 1,31 & 0,08 & 3,44\end{array}$

b) Anālise física

\begin{tabular}{lllcl} 
Solos & Areia & Limo & Argila & $\begin{array}{l}\text { Classificação } \\
\text { Textural }\end{array}$ \\
\hline PVA & 82,4 & 11,5 & 6,1 & $\begin{array}{l}\text { Areiabarrenta } \\
\text { LE }\end{array}$ \\
\hline 39,3 & 24,3 & 36,4 & Barro argiloso
\end{tabular}

c) Anālise mineralógica da fração argila la

\begin{tabular}{|c|c|c|c|c|c|c|c|}
\hline Solos & $\begin{array}{c}\text { Horizon } \\
\text { te }\end{array}$ & $\begin{array}{l}\text { Cauli- } \\
\text { nita }\end{array}$ & Gibbsita & Mica & $\begin{array}{c}\text { Vermicu- } \\
\text { lita }\end{array}$ & $\begin{array}{l}\text { Montmo } \\
\text { rilonita }\end{array}$ & $\begin{array}{c}\text { Alof } \\
\text { na }\end{array}$ \\
\hline \multirow[t]{3}{*}{ PVA } & $A p$ & 61,5 & 14,5 & 9,9 & 6,2 & 2,4 & 6,8 \\
\hline & $A_{3}$ & 47,0 & 8,0 & 10,3 & 18,0 & 4,6 & 5,7 \\
\hline & $B_{22}$ & 54,5 & 15,0 & 8,9 & 12,0 & 2,7 & 5,9 \\
\hline \multirow[t]{2}{*}{ LE } & $A p$ & 79,5 & 15,5 & 0,4 & 0,6 & 0,0 & 5,1 \\
\hline & $B_{22}$ & 78,0 & 15,0 & 0,8 & 1,4 & 0,0 & 5,0 \\
\hline
\end{tabular}

a/Fonte: ALOISI et alii (1975) 
Estes solos apresentam teores médios de fósforo. Fertilidade média (LE) e baixa (PVA) e teores médio e ba i xo de óxidos de ferro $(2.5 \%$ e $0.86 \%)$ respectivamente.

\subsection{ADUBOS}

Em todos os ensaios, uma adubação com NPK foi aplicada. Como fontes de fósforo foram utilizados ofosfatomo nopotássico e o fosfato monocálcico como fontes de 31 pe o fos fato monosódico como fonte de 32 p. Como fontes de nitrogênio foram usadas a uréia e o sulfato de amônio. Como fonte de potássio foi usado o cloreto de potássio. Todos foram aplicados na forma liquida.

\subsection{METODOLOGIA}

\subsubsection{Primeiro ensaio}

3.3.1.1. Delineamento experimental

o ensaio obedeceu a um delineamento experimen-

tal inteiramente casualizado e o esquema de análise foi do tipo fato $\bar{r} i a l(3 \times 2 \times 2)$ com 12 tratamentos, para cada solo,e três repetições tendo como variáveis:

1) Três niveis de carregador: 0,0-0,13 e $1,33 \mathrm{ppm}$ de $\mathrm{P}$. 
2) Duas espécies de plantas: feijão cr. Carioca; arroz CV. IAC -25

3) Duas épocas de colheita: 30 e 50 dias após o plantio.

3.3.1.2. Tratamentos

1) Arroz - 30 dias - sem fósforo ( $\left.P_{0}\right)$

2) Arroz - 30 dias - 0.13 ppm de fósforo ( $\left.P_{0.13}\right)$

3) Arroz - 30 dias - 1.33 ppm de fósforo ( $\left.p_{1.33}\right)$

4) Arroz - 50 dias - sem fósforo ( $\left.P_{0}\right)$

5) Arroz - 50 dias - $0.13 \mathrm{ppm}$ de fósforo ( $\left.P_{0.13}\right)$

6) Arroz - 50 dias - 1.33 ppm de fósforo ( $\left.P_{1} .33\right)$

7) Feijão - 30 dias - sem fósforo ( $\left.P_{0}\right)$

8) Feijão - 30 dias - 0.13 ppm de fósforo ( $\left.P_{0.13}\right)$

9) Feijão - 30 dias - 1.33 ppm de fósforo ( $\left.P_{1.33}\right)$

10) Feijão - 50 dias - sem fósforo $\left(P_{0}\right)$

11) Feijão - 50 dias - 0.13 ppm de fósforo ( $\left.P_{0.13}\right)$

12) Feijão - 50 dias -1.33 ppm de fósforo $\left(P_{1.33}\right)$

3.3.1.3. Procedimento

Foram preparadas três soluções contendo cada uma $0,5 \mathrm{mCi}$ de $32 \mathrm{p} / 1 \mathrm{it} \bar{r} \mathrm{o}$. A seguir adicionou-se na primeiraso lução $20 \mathrm{mg}$ de $31 \mathrm{p}$ e na segunda $200 \mathrm{mg}$ de $31 \mathrm{p}$ a partir defosfato monopotássico. A terceira solução ficou livre de cạrega dor.

os vasos de barro, impermeabilizados com neu- 
trol, tinham capacidade para $3 \mathrm{~kg}$ de terra. Esta foi separada em quatro porções aproximadamente iguais de 700 g. Sobre a pr meira porção ou camada, aplicou-se $5 \mathrm{ml}$ de uma das 3 soluções preparadas anteriormente de acordo com o esquema experimental. Sobre a segunda porção ou camada aplicou-se mais $5 \mathrm{ml}$ e sobre a terceira porção ou camada mais $10 \mathrm{ml}$. A seguir colocou-se a quarta porção ou camada. Sobre essa última camada foram colocadas 15 sementes de arroz e 7 de feijão, nos vasos respectivos. O restante do solo (200 g) foi colocado sobre as sementes. Estas operaçöes foram repetidas 108 vezes. Cada solo foi logo umedecido à $75 \%$ da sua capacidade de embebição. No dia seguinte adicionou-se a cada vaso uma solução contendosul fato de amónio e cloreto de potássio, equivalente a 80 e $60 \mathrm{~kg}$ Tha de $\mathrm{N}$ e $\mathrm{K}_{2} \mathrm{O}$ respectivamente.

oito dias após o plantio, foi feito o desbaste deixando-se 10 plantas de arroz e 4 de feijão porvaso. Foram feitos tratamentos fitossanitários com produtos livres de fósforo e regas periodicas. Os vasos foram trocados de posi çào na estufa cada oito dias.

Na época de colheita $(30$ e 50 dias após o plan tio), cortou-se a parte aérea das plantas, l cmacima do so10, as quais foram colocadas em sacos de papel e secas em estufa a 65:C, durante 72 horas. A seguir as amostras foram pesadas e moidas no moinho willey malha n? 20. Posteriormente, uma grama de cada foi digerida por digestão nitroperclórica, levando-se a um balão volumétrico de $50 \mathrm{ml}$ com àgua destila- 
da, guardando-se a seguir, o substrato obtido em frascos de vi dro. Tomou-se alíquotas de $20 \mathrm{ml}$ para a determinação da radio atividade do $32 p$ no contador de cintilação líquida Beckman LS230, pelo efeito Cerenkov. Também foram tomadas alíquotas de 2 ml para a determinação do P-total pelo método do vanadatomolibdato no colorimetroklett Summerson com filtro n? 42, de acordo com o método descrito em LOTT et alii (1956).

\subsubsection{Segundo ensaio}

\subsubsection{Delineamento experimental}

o ensaio obedeceu a um delineamento experimental inteiramente casualizado e o esquema de análise foi do ti po fatorial $(3 \times 3 \times 2)$ com 18 tratamentos para cada solo e três repetiçōes tendo como variáveis:

1) Três niveis de carregador: zero (0); 22 e 220 ppm de P.

2) Três niveis de nitrogênio: zero (0); 50 e $100 \mathrm{~kg} \mathrm{~N} / \mathrm{ha}$.

3) Duas fontes de nitrogênio: uréia e sulfato de amōnio

3.3.2.2. Tratamentos

1) Sem N-urēia - sem fósforo

$\left(P_{0}\right)$

2) Sem N-urēia - 22 ppm de fósforo

$\left(P_{22}\right)$

3) Sem N-urēia - 220 ppm de fösforo 

4) $50 \mathrm{~kg} \mathrm{~N}$-urēia - sem fösforo
$\checkmark$
$\left(P_{0}\right)$
5) $50 \mathrm{~kg} \mathrm{~N}$-uréia - $22 \mathrm{ppm}$ de fösforo
$\left(\begin{array}{l}P_{2} 2 \\ 2\end{array}\right.$
6) $50 \mathrm{~kg} \mathrm{~N}$-urēia - 220 ppm de fósforo
$\left(P_{2} 20\right)$
7) $100 \mathrm{~kg} \mathrm{~N}$-uréia - sem fösforo
$\left(P_{0}\right)$
8) $100 \mathrm{~kg} \mathrm{~N}$-uréia - $22 \mathrm{ppm}$ de fósforo
$\left(P_{2} 2\right)$
9) $100 \mathrm{~kg} \mathrm{~N}-u r e ̄ i a-220 \mathrm{ppm}$ de fösforo
$\left(P_{2} 20\right)$
10) Sem N-sulfato Am. - sem fösforo
$\left(P_{0}\right)$
11) Sem N-sulfato Am. - 22 ppm de fósforo
$\left(P_{22}\right)$
12) Sem N-sulfato Am. - 220 ppm de fósforo
$\left(\begin{array}{llll}P & 2 & 2 & 0\end{array}\right)$
13) $50 \mathrm{~kg} \mathrm{N-sulfato} \mathrm{Am.} \mathrm{-} \mathrm{sem} \mathrm{fösforo}$
$\left(P_{0}\right)$
14) $50 \mathrm{kgN}$-sulfato Am. - $22 \mathrm{ppm}$ de fósforo
$\left(P_{22}\right)$
15) $50 \mathrm{~kg} \mathrm{~N}$-sulfato Am. - $220 \mathrm{ppm}$ de fösforo
$\left(\begin{array}{llll} & 2 & 2 & 0\end{array}\right)$
16) $100 \mathrm{~kg} \mathrm{~N}$-sulfato Am. - sem fösforo
$\left(P_{0}\right)$
17) $100 \mathrm{~kg} \mathrm{~N}$-sulfato Am. - 22 ppm de fósforo
$\left(P_{2} 2\right)$
18) $100 \mathrm{~kg} \mathrm{~N}$-sulfato Am. - 220 ppm de fósforo
$\left(\begin{array}{llll}P & 2 & 2 & 0\end{array}\right)$

\section{$3 \cdot 3 \cdot 2 \cdot 3$. Procedimento}

As soluçōes com diferentes niveis de carregador foram preparadas como no ensaio 1 . Usou-se o fosfato mono càlcio como carregador e a atividade final aplicada foi de 10,4 HCi por vaso. As soluçōes de uréia e sulfato de amónio em dose segundo o- tratamento e o cloreto de potássio em dose de $60 \mathrm{~kg} \mathrm{~K}_{2} 0 / \mathrm{ha}$ foram aplicadas na superficie do solo.

As plantas foram colnidas aos 35 dias apōs o plantio, secas, pesadas, moidas, digeridas e analisadas como indicado no item 3.3 .1 .3 . 


\subsubsection{Terceiro ensaio}

3.3.3.1. Delineamento experimental

Ensaio com um delineamento experimental e es-

quema de anälise inteiramente casualizado com 5 tratamentos (5,5 $11-33-66$ e 99 ppm de P) e três repetiçōes. 0 solo podzoli zado e o arroz foram utilizados.

3.3.1.2. Procedimento

As soluçōes foram preparadas como no experimenn to n? 1. Usou-se fosfato monocälcico como carregador. A radio atividade aplicada foi de 6,76 HCi por vaso. Os controles fitossanitários, colheita e análise foram feitos como no item $3 \cdot 3 \cdot 1.3$.

\subsubsection{Quarto ensaio}

\subsubsection{Delineamento experimental}

o ensaio obedeceu a um delineamento experimental inteiramente casualizado e o esquema de anälise do tipo fatorial $(3 \times 3 \times 2)$ com 18 tratamentos e três repetiçōes com as seguintes variàveis:

1) Três niveis de carregador: 0,1 - 5 e 10 ppm de P.

2) Duas espëcies de plantas e duas condiçōes para a cultura de arroz (submersão - sequeiro).

3) Dois solos: PVA e LE: 
3.3.4.2. Tratamentos
a) Ensaio no PVA
Ensaio no LE
1) Arroz-sequeiro - $P_{0.1}$
1) Arroz-sequeiro- $P_{0.1}$
2) Arroz-sequeiro - $P_{5}$
2) Arroz-sequeiro- $P_{5}$
3) Arroz-sequeiro-P10
3) Arroz-sequeiro - Plo
4) Arroz-submersão - $P_{0.1}$
4) Arroz-submersão- $P_{0} .1$
5) Arroz-submersão- $P_{5}$
5) Arroz-submersão - $P_{5}$
6) Arroz-submersão-P 10
6) Arroz-submersão - P 10
7) Feijão-sequeiro- $P_{0.1}$
7) Feijão-sequeiro-Po.
8) Feijão-sequeiro-P 5
8) Feijão-sequeiro-P 5
9) Feijão-sequeiro-P,o
9) Feijão-sequeiro-P 10

\subsubsection{Procedimento}

Foram preparadas très soluções que continhamos niveis de carregador acima citados a partir de fosfato monopotássico as quais foram marcadas com 32 p para dar uma ativi dade final de $6 \mu \mathrm{Ci} / \mathrm{ml}$. Logo depois foram adicionados $2 \mathrm{ml}$ destas soluçōes a porçōes de solo de $50 \mathrm{~g}$ que atravessaram pe neira n? 18 as quais foram secas em estufa a 65:C por duas ho ras. A seguir foram adicionadas à outra porção de solo $(2,950$ kg) que já estavam em sacos plästicos. As duas porçōes de solo foram misturadas, manualmente, a té obter uma mistura tãoho mogēnea possivel, e a seguir colocadas nos vasos respectivos e tratadas como no item 3.3.1.3. No dia seguinte, aplicaram- se soluções contendo o equivalente a $100 \mathrm{~kg}$ de $\mathrm{N}$ e $100 \mathrm{~kg}$ de $\mathrm{K}_{2} \mathrm{O}$ nas formas de uréia e cloreto de potássio respectivamente. 
Apōs o desbaste, a metade dos vasos plantados com arroz foram inundados com uma làmina de água de $1-2$ cm e aajim mantidos até a colheita. Foram feitos controles fitossa . Aários e análises como no ensaio n? l, item 3.3.1.3.

3.4. CALCULO DO VALOR 'L'

o cálculo do valor 'L', quando foi usado carre gador, foi feito de acordo coma equação 5, pág. 6, de RUSSELL et ali i (1957):

$$
L=\frac{Y f(X p-D)}{Y_{P}}-X_{f}
$$

onde: $L$ = fósforo isotopicamente trocável (mg P/kg solo)

$Y f=32 p$ aplicado ao solo (c/min/kg solo)

$Y p=32 p$ nas plantas $(c / m i n)$

$X f=3 l p$ aplicado ao solo como carregador (mg P/kg solo)

$x p=31 p$ nas plantas (mg)

$D=31$ p nas sementes (mg)

ou seja: $\frac{\mathrm{mg} P}{\delta k g \text { solo }}=\frac{\mathrm{c} / \mathrm{min} / Z \mathrm{~kg} \mathrm{solox}(\mathrm{mgP}-\mathrm{mgP})}{\mathrm{c} / \mathrm{min}}-\frac{\mathrm{mgP}}{\text { zkg solo }}$

Para estimar o valor de D, considerou-se que 65\% e 20\% do fósforo do endosperma das sementes de arroz e fei jāo, respectivamente, translocaram-se à parte aērea.

$$
\text { Quando não foi usado carregador, o cálculo do }
$$


valor 'L' foi feito de acordo com a expressão de Sokolov (1958) modificada por NEPTUNE e CAMPANELLI (1961)

$$
L=\frac{Y f}{s p} \quad \text { onde sp }=\frac{Y p}{X p-D}
$$

sp = atividade especifica na planta (c/min/g)

\subsection{ANALISE ESTATISTICA}

A anälise estatistica dos esquemas fatoriais foi interpretada de acordo com CALZADA (1964). Somente foram analisadas as seguintes variāveis: produção de material vegetal seco, fösforo total e valor 'L'. 
27.

\section{RESULTADOS E DISCUSSÃO}

4.1. PRIMEIRO ENSAIO

Avaliaçào do efeito de baixos niveis de carregador, da espécie de planta e da época de colheita na determi nação do valor ' $L$ ' nos solos PVA e LE.

4.1.1. No solo Podzolizado

As anàlises de variância dos resultados, revelaram através do teste $F$, serem significativos ao nivel de $1 \%$ de probabilidade, os efeitos da espécie de planta (c), da épo ca de colheita (E) e da suá interação C X E sobre os parāmetros analisados: material vegetal seco (MVS) fósforo total e valor 'L'; interação niveis de fósforo (P) por espécie de plan ta (C.) por época de colheita $(P X C X E)$ no teor de $P$ to- 
tal e os efeitos de niveis de $P$ e as interações $P X C$ e $P$ X sobre o valor 'L'. (Veja-se no apêndice 1 e 4).

Na tabela 2, observa-se que os baixos niveis de carregador não causaram nenhum efeito sobre as produções de material vegetal seco (M.V.S.) obtidos dos tratamentos; houve diferença entre estes, no que diz respeito às épocas de coIheita no arroz e às duas espécies de plantas na colheita fei ta aos 50 dias. A semelhança nas produções de M.V.S. entre. as duas ëpocas no feijoeiro deve-se provavelmente à perda de foIhas velhas depois dos 25 dias de idade. Na figura la, observa-se a distribuição dos vasos para a colheita de 50 dias e o feijoeiro quase só com as folhas mais novas.

o teor de $P$ total nas plantas foi similar para os três niveis de p dentro de cultura e época. Dados mostrando resultados semelhantes tem sido relatados por MALEINA (1958). Este pesquisador não encontrou efeito na absorção de $P$ quando aplicou doses pequenas de carregador. Porém, os teores de P total foram significativamente diferentes entre as duas ëpocas no arroz e entre as duas culturas na colheita aos 50 dias. De fato, o pequeno incremento do M.V.S. no feijoeiro aos 50 dias causou também pequeno aumento nos teores de $P$ total.

A semelhança entre os valores de M.V.S. e P to tal pode ser devida a que os baixos niveis de p não alteraram o sistema fósforo do solo porque o aporte do p aplicado não foi significante. Não entanto a diferença na absorção de $P$ e na produção de M.V.S. das espécies de plantas tem sido reco- 
Tabela 2. Ensaio 1. Quantidade de material vegetal seco (MSV), porcentagem de fósforo (\%), fósforo total, atividade especifica (sp) e valor 'L' dos tratamentos noso solo podzolizado

\begin{tabular}{|c|c|c|c|c|c|c|c|}
\hline \multicolumn{3}{|c|}{ TRATAMENTO } & \multirow[b]{2}{*}{$\begin{array}{l}\text { MVS } \\
\text { (g/ } \\
\text { vaso) }\end{array}$} & \multirow[b]{2}{*}{$\approx P$} & \multirow[b]{2}{*}{$\begin{array}{c}P \text {-total } \\
\text { (mg/ } \\
\text { vaso) }\end{array}$} & \multirow[b]{2}{*}{$\begin{array}{c}\mathrm{sp} \\
(\mathrm{c} / \\
\mathrm{min} / \mathrm{g})\end{array}$} & \multirow[b]{2}{*}{$\begin{array}{c}\text { Valor L } \\
(m g P / \\
\text { kg solo) }\end{array}$} \\
\hline Cultura & $\begin{array}{l}\text { Idade } \\
\text { de } \\
\text { Colheita }\end{array}$ & $\begin{array}{c}\text { Niveis } \\
\text { de } \\
\text { carre } \\
\text { gador }\end{array}$ & & & & & \\
\hline 1) Arroz & - 30 dias & $P_{0}$ & 2,92 & 0,268 & 5,56 & - 22721 & 23,00 \\
\hline 2) Arroz & - 30 dias & $P_{0.13}$ & 2,01 & 0,254 & 4,62 & 31154 & 18,33 \\
\hline 3) Arroz & - 30 dias & $P_{1.33}$ & 1,90 & 0,237 & 4,04 & 46368 & 11,33 \\
\hline 4) Arroz & - 50 dias & $P_{0}$ & 8,06 & 0,107 & 8,08 & 9071 & 26,33 \\
\hline 5) Arroz & - 50 dias & $P_{0.13}$ & 7,72 & 0,127 & 9,21 & 11930 & 21,33 \\
\hline 6) Arroz & - 50 dias & $P_{1.33}$ & 7,79 & 0,135 & 9,98 & 15644 & 16,66 \\
\hline 7) Feijão & - 30 dias & $P_{0}$ & 3,25 & 0,116 & 2,88 & 4995 & 103,66 \\
\hline 8) Feijão & - 30 dias & $P_{0.13}$ & 3,00 & 0,120 & 2,71 & 11698 & 51,66 \\
\hline 9) Feijão & - 30 dias & $P_{1.33}$ & 3,00 & 0,120 & 2,73 & 24490 & 25,00 \\
\hline 10) Feijão & - 50 dias & $P_{0}$ & 3,62 & 0,123 & 3,57 & 4321 & 55,33 \\
\hline 11) Feijão & - 50 dias & $P_{0.13}$ & 4,75 & 0,094 & 3,63 & 6691 & 39,00 \\
\hline 12) Feijão & - 50 dias & $P_{1.33}$ & 3,93 & 0,104 & 3,23 & 11694 & 23,00 \\
\hline d.m.s. (Tuk & key $5 \%$ & & 1,54 & & 1,94 & & 15,98 \\
\hline C.V. & & & 12,09 & & 13,00 & & 15,56 \\
\hline
\end{tabular}


a)

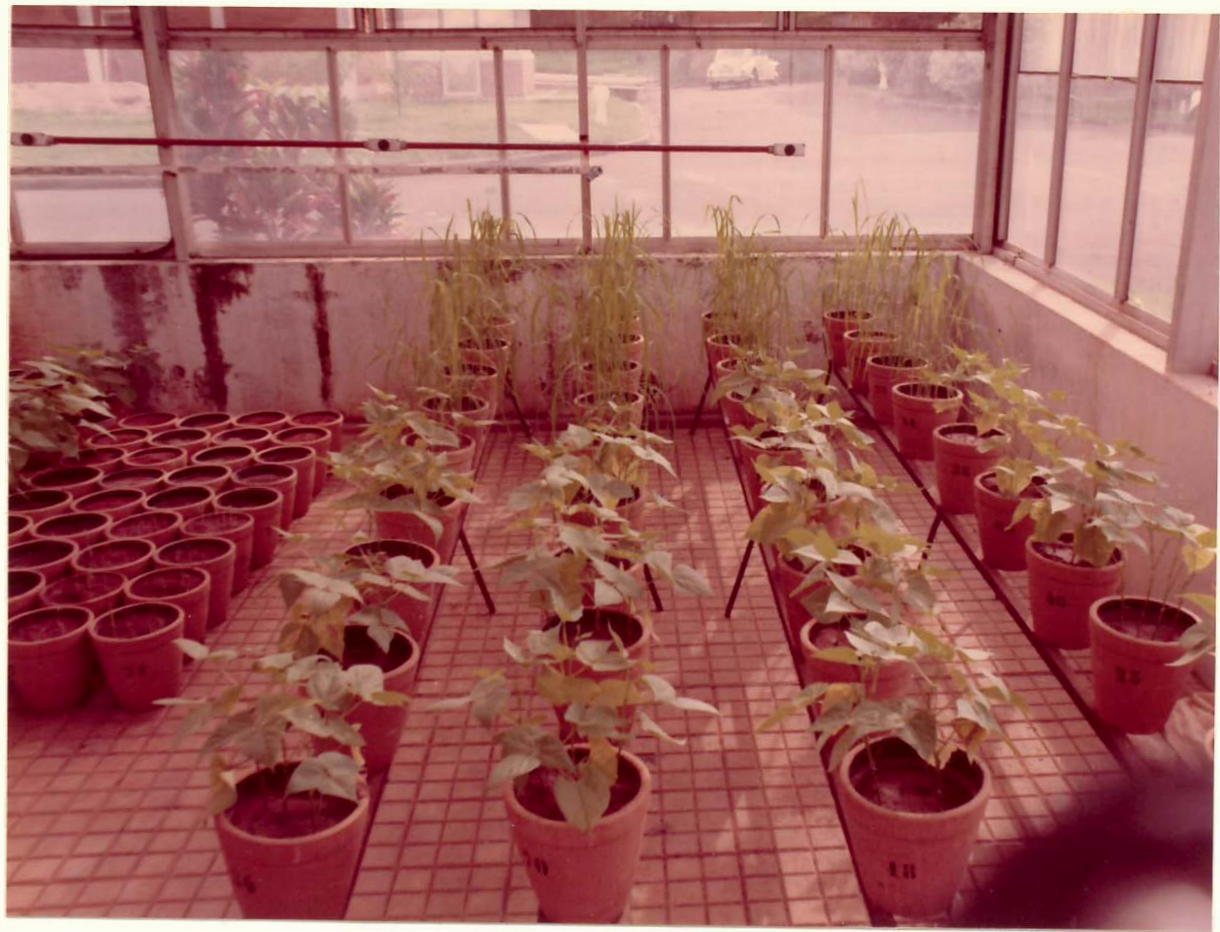

b )

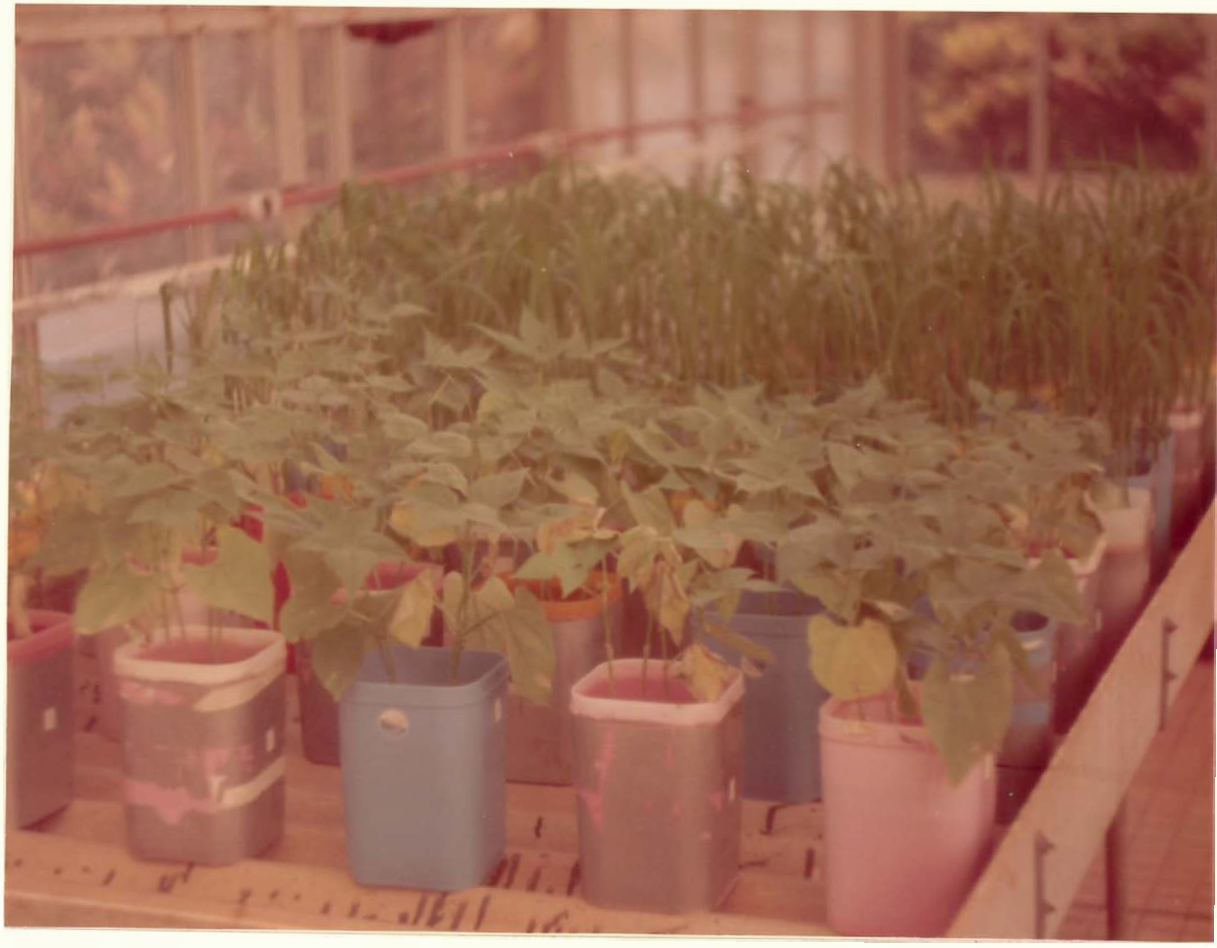

Figura 1. Distribuiçào dos vasos na casa de vegetaçäo: a) prí meiro ensaio, colheita aos 50 dias; bl quarto ensaio. 
nhecida por muitos pesquisadores (DEAN et alii , 1948; NELSON et alii, 1948; MATTINGLY e TALIBUDEEN, 1960; RUSSELL, 1963 e ElD et alii, 1965) segundo NYE e FOSTER (1958), BAKER (1964) e KALRA e SOPER (1968) a quantidade de fósforo absorvido do fertilizante depende da idade e do tipo de cultura.

As porcentagens de $P$ nas duas plantas, de maneira geral, foram baixas no feijoeiro $(0.115)$ e medios no arroz (0.253), diminuindo com a idade da planta atè o nível de deficiéncia no arroz $(0.123)$, devido provavelmente ao efei to de diluição.

As atividades especificas nas plantas, em todos os casos, aumentaram com o incremento nos níveis de carre gador e foram maiores para o arroz do que para o feijoeiro. 0 que sugere que de um lado o equilibrio isotōpico não foi atin gido o que de outro as plantas absorveram $P$ de outras fontes não disponíveis nos primeiros trinta (30) dias.

os valores ' $L$ ' diminuiram com o incremento no nível de carregador nas duas épocas e nas duas culturas (fig. 2a). Estes resultados não concordam com os obtidos por outros pesquisadores que tem encontrado efeitos não significativosde niveis baixos de carregador (SOKOLOV, 1958; MALEINA, 1958; MARAIS et alii, 1969). Embora, SELVARATNAM et alii (1981) encontraram diminuição dos valores 'L' com aumento do nível de carregador.

os niveis baixos de carregador e a época da co lheita não causaram nenhum efeito sobre os valores 'L' quando 


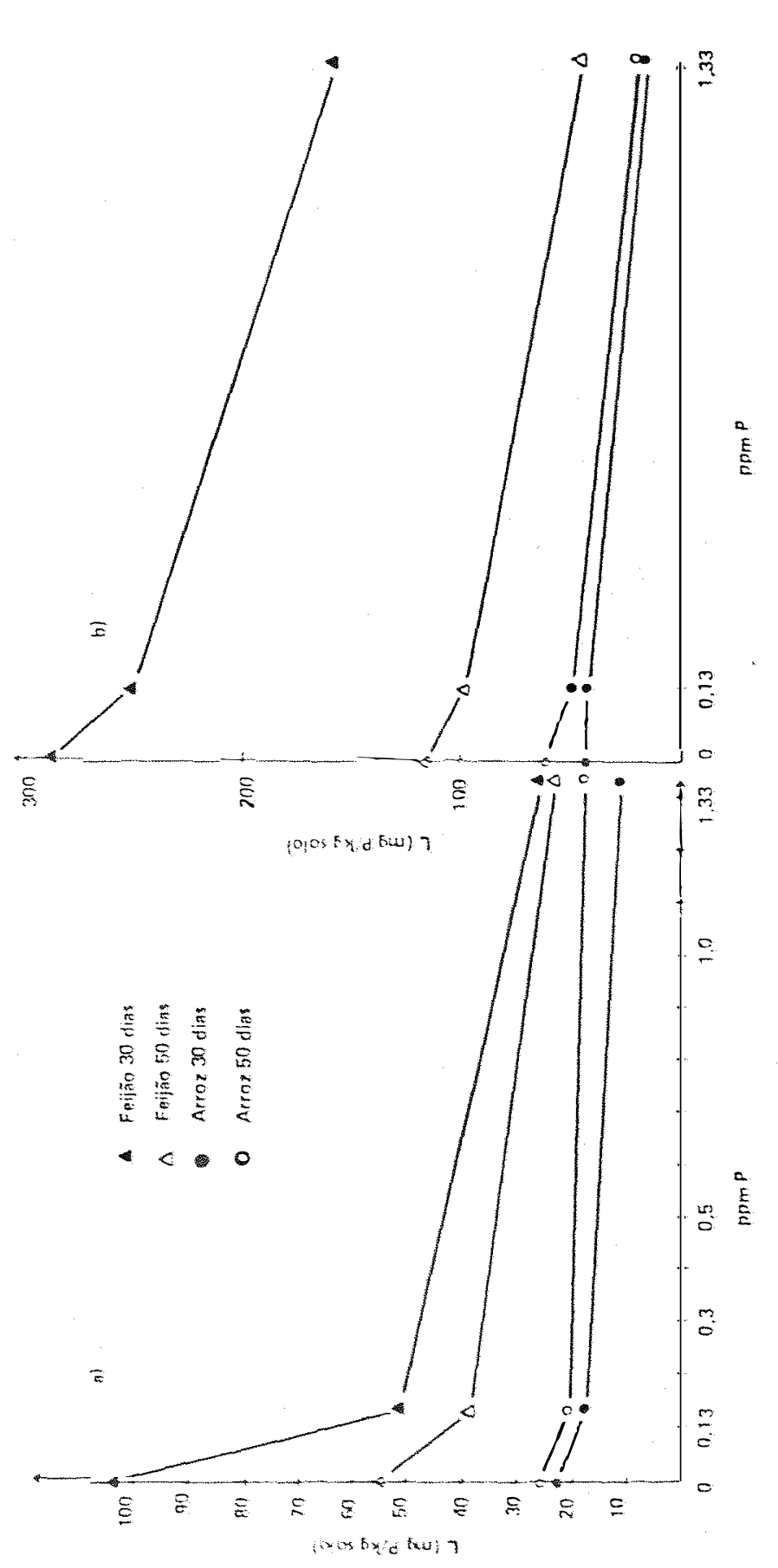

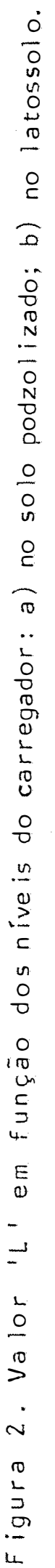


a cultura utilizada foi o arroz, mas ocorreu o conträrio com o feijoeiro, onde apresentou-se diferenças entre os tratamentos em cada época e entre as épocas quando o tratamento ficou livre de carregador. RUSSELL et alii (1958) encontraram que os valores ' $L$ ' permanecem constantes com espécies de plantas, ao longo do experimento (atē 56 dias) mas os valores 'L' entre as espécies foram diferentes segundo sua capacidade para absorver fósforo.

Comparando os valores 'L' com os dados obtidos pelo método de extração quimica, utilizando $\mathrm{H}_{2} \mathrm{SO}_{4} 0.05 \mathrm{~N}$ de acordo com CATAN et ali i (1955), Tabela 1 página 17 , nota-se que o valor 'L' obtido com l,33 ppm de p como carregador aos 30 dias e com a cultura do arroz foi idēntico ao obtido quimicamente (11.6 ppm). De outro lado, os valores 'L' forammaio res quando o nivel de carregador foi quase insignificante e principalmente quando a cultura utilizada foi o feijoeiro. Pa ra MEKHAEL et ali i (1965) e AMER et ali i (1969), o método de SOKOLOV (livre de carregador) superestima o fósforo isotopicamente trocável.

\subsubsection{No Latossolo}

A anàlise de variància dos resultados mostrou, através do teste $F$, o efeitó significativo a $1 \%$ das doses de P na cultura de arroz, da época de colheita (E), da espécie de planta (C) e da interaçãoc XE no M.V.S. e teor de P total, e 
dos niveis de P, da espécie de planta, da época de colheita e das interaçōes $P X C$ e $C X E$ sobre os valores 'L'. (Veja-se no apêndice 1 e 4).

Segundo a tabela 3 , verifica-se que a produção de M.V.S. das plantas foi similar nos très níveis de P. Como no solo podzölizado, houve diferença significativa entre as duas épocas de colheita somente no arroz. A semelhança entre as produções de M.V.S. nas duas ëpocas no feijoeiro foram devidas, provavelmente as folhas velhas que cairam a partir dos 25 dias, as quais não foram computadas para évitar maior diminuição nos cälculos das atividades especificas. A fig. 1 b mostra as folhas velhas completamente secas e prontas a cair. Na mesma tabela nota-se que o teor de P total nas plantas foi semelhante para os très niveis de $P$. Porém, houve diferença significativa entre as duas épocas de colheita para os tratamentos que receberam zero e 0.13 ppm de $P$ no arroz. Estes resultados eram esperados, se considerarmos que o aumento de $P$ do solo pelos tratamentos foi quase insignificante. Porém, os teores de P total encontrados neste solo foram menores que no P.V.A.

Embora a anälise quimica mostrara que este solo tem teor médio de fösforo $(13,9$ ppm), nas duas espécies de plantas foram encontradas porcentagens de $P$ baixas, sendo 'mui to menores no arroz colhido aos 50 dias. As duas espécies de plantas apresentaram coloração verde-amarelada quando quando deixadas até os 50 dias. Para NYE e FOSTER (1958) a difee 
Tabela 3. Ensaio 1. Quantidade de material vegetal seco (MVS), porcentagem de fósforo (\%P), fósforo total, atividade especifica (sp) e valor ' $L$ ' dos tratamentos no latossolo

TRATAMENTO

\begin{tabular}{|c|c|c|c|c|c|c|c|}
\hline Cultura & $\begin{array}{l}\text { Idade } \\
\text { de } \\
\text { Colheita }\end{array}$ & $\begin{array}{c}\text { Niveis } \\
\text { de } \\
\text { carre } \\
\text { gador }\end{array}$ & $\begin{array}{c}\text { MVS } \\
\text { (g/ } \\
\text { vaso) }\end{array}$ & qP & $\begin{array}{c}\text { P-total } \\
\text { (ming/ } \\
\text { vasol }\end{array}$ & $\begin{array}{c}\mathrm{sp} \\
(\mathrm{c} / \\
\mathrm{min} / \mathrm{g})\end{array}$ & $\begin{array}{c}\text { Valor L } \\
\text { (mg P) } \\
\text { kg solo }\end{array}$ \\
\hline 1) Arroz & - 30 dias & $P_{0}$ & 1,12 & 0,118 & 0,85 & 12351 & 42,66 \\
\hline 2) Arroz & - 30 dias & $P_{0.13}$ & 1,50 & 0,127 & 1,41 & 13898 & 42,00 \\
\hline 3) Arroz & - 30 dias & $P_{1.33}$ & 1,46 & 0,153 & 1,80 & 42349 & 14,00 \\
\hline 4) Arroz & - 50 dias & $P_{0}$ & 4,18 & 0,079 & 2,84 & 3895 & 61,00 \\
\hline 5) Arroz & - 50 dias & $P_{0.13}$ & 4,83 & 0,077 & 3,24 & 5281 & 49,33 \\
\hline 6) Arroz & - 50 dias & $P_{1.33}$ & 4,99 & 0,070 & 2,94 & 14830 & 17,66 \\
\hline 7) Feijāo & - 30 dias & $P_{0}$ & 3,01 & 0,101 & 2,18 & 1838 & 287,00 \\
\hline 8) Feijāo & - 30 dias & $P_{0.13}$ & 2,92 & 0,097 & 1,98 & 2297 & 253,33 \\
\hline 9) Feijāo & - 30 dias & $P_{1.33}$ & 3,03 & 0,097 & 2,09 & 3931 & 157,00 \\
\hline 10) Feijāo & - 50 dias & $P_{0}$ & 2,95 & 0,116 & 2,60 & 2074 & 116,33 \\
\hline 11) Feijāo & - 50 dias & $P_{0.13}$ & 2,89 & 0,101 & 2,04 & 2634 & 99,33 \\
\hline 12 ) Fei jão & - 50 dias & $P_{1.33}$ & 2,97 & 0,108 & 2,35 & 5971 & 46,33 \\
\hline d.m.s. (Tuk & (ey 5\%) & & 0,95 & & 1,62 & & 56,92 \\
\hline C.V. $\%$ & & & 10,83 & & 24,85 & & 19,37 \\
\hline
\end{tabular}


rença de absorção de fösforo, especialmente em solos muito po bres, sugere que certas espécies são mais eficientes que outras na absorção de $P$ do solo de baixo potencial neste elemen to.

Como no solo podzolizado, houve um aumento nas atividades específicas nas plantas com o incremento no nivel de P, nas duas culturas e nas duas épocas.

Quanto aos valores 'L' não foram diferentes pạ ra os tratamentos em que o arroz foi utilizado como planta in dicadora, mas totalmente diferentes para o feijoeiro. 0s valores ' $L$ ' diminuiram com o incremento no nivel de carregador nas duas culturas e nas duas épocas de colheita (Fig. 2b). Dados semelhantes tem sido observados na literatura (AMER et ali i, 1969 e SELVARATNAM et alii, 1981). Para RUSSELL et ali i (1957), os altos valores ' $L$ ' obtidos com pequenas quantidades de $P$ adicionado são devidas a fixação do p pelo solo.

os valores ' $L$ ' foram diferentes entre as duas espécies de planta, sendo maiores para o feijoeiro do que para o arroz, e, entre as duas épocas de colheita para todos os niveis de $P$ no feijoeiro. Foram semelhantes para o arroz inde pendentemente da época de colheita. Muitos pesquisadores relataram o efeito da espécie de planta nos valores 'L', assim foram encontradas entre gramíneas diferenças na resposta aos fosfatos (MITCHELL, 1957 ). 
4.2. SEGUNDO ENSAIO

Avaliação do efeito de três niveis de carregador, três doses e duas fontes de Nitrogênio na determinação do valor ' $L$ ' usando arroz como planta indicadora.

\subsubsection{No Solo Podzolizado}

A anālise de variància dos resultados revelou, através do teste $F$, serem significativos ao nivel de $1 \%$ de probabilidade os efeitos de niveis de p sobre os trés paràmetros analisados: M.V.S., P total e valor 'L'. Da interação $P X N$ sobre os teores de P total e valor 'L'; e as dosesefon tes de $N$ e a interação $P X F$ sobre os teores de $P$ total (Ve ja-se no apêndice 2 e 5).

Na tabela 4, encontram-se os dados da produção

de M.V.S. para os tratamentos. Houve aumento no M.V.S. com o incremento nas doses de $N$ e de $P$. Não houve efeito dos niveis de $P$ quando os tratamentos não receberam Nitrogénio ou quando a fonte foi o sulfato de amōnio. Houve efeito dos niveis 22 e 220 ppmi de $P$ quando o nivel de $N$ foi de $50 \mathrm{~kg} / \mathrm{ha}$ e a fonte a Uréia; e do nível $22 \mathrm{ppm}$ de $P$ sö, quando a dose foi de 100 kg de N-Uréia. Houve efeito da dose $100 \mathrm{~kg}$ de $\mathrm{N}$ no nível zero ppm de $P$ quando a fonte foi o sulfato de amónio e nos níveis 22 e 220 ppm de $P$ quando a fonte foi a Uréia.

$$
\text { Este efeito do aumento de produção de M.V.S. }
$$


com o carregador até 20 ppm foi mencionado por MEKHAEL etali i (1965). E importante salientar que houve uma diminuição na produção de M.V.S. quando o nivel de carregador foi 220 ppm e o nivel de $N$ foi de $50 \mathrm{~kg} / \mathrm{ha}$ e maior quando a fonte foi o sul fato de amónio. As plantas de arroz, adubadas com sulfato de amōnio, apresentaram uma coloração grisäcea e encarquilhamento semelhante ao produzido pela seca embora tiveram suficiente umidade.

E de se acreditar que esse sintoma seja devido a um excesso de fósforo no solo. De fato a dóse de 220 ppm de P corresponde aproximadamente a uma quantidade de $500 \mathrm{~kg}$ P/ha ou $1.265 \mathrm{~kg} \mathrm{P}_{2} \mathrm{O}_{5}$ /ha. Por outro lado, a porcentagem de fósforo na planta de alguns destes tratamentos foi acima de $1 \%$ quando o teor de uma planta normal é de $0.25 \%$. Igualmente foram observados altos teores de Potássio ( $3.13 \%)$, Magnésio $(0.6 \%)$, Manganès $(800 \mathrm{ppm})$ e zinco (77 ppm).

Segundo a tabela 4, os teores de P total aumen taram com o incremento nos niveis de $P$ e de N. Houve efeito significativo do nivel de 220 ppm de $P$ independente da dose e fonte de $N$ e do nivel de 22 ppm de $P$ na dose de $100 \mathrm{~kg}$ de N-Uréia. Não houve efeito das doses nem das fontes de $N$ nos niveis zero e 22 ppm de $p$, mas sem no nivel de 220 ppm de p onde apresentou-se diferença entre os niveis de 50 e $100 \mathrm{~kg}$ de N-Urëia; entre cada um dos niveis de N-sulfato de Am; e entre as duas fontes no nivel de $100 \mathrm{~kg}$ de $\mathrm{N}$.

Deve-se salientar que a maior absorção de p pe 
Tabela 4. Ensaio 2. Quantidade de Material Vegetal seco (MVS), porcentagem de fósforo (\%p), fósforo total, ativida de especifica (sp) e valor 'L' dos tratamentos noso lo podzolizado

TRATAMENTO

\begin{tabular}{|c|c|c|c|c|c|c|}
\hline $\begin{array}{l}\text { Nivel de } \\
\text { carre- } \\
\text { gador }\end{array}$ & \multirow{2}{*}{$\begin{array}{c}\begin{array}{c}\text { Fonte e } \\
\text { dose de } \\
N\end{array} \\
\text { Uréian }\end{array}$} & \multirow{2}{*}{$\begin{array}{r}\text { MVS } \\
\text { (g/ } \\
\text { vaso) } \\
3,54\end{array}$} & \multirow{2}{*}{$\frac{5}{0,218}$} & \multirow{2}{*}{$\begin{array}{c}\begin{array}{c}P \text {-total } \\
(\mathrm{mg} / \\
\text { vaso) }\end{array} \\
7,23\end{array}$} & \multirow{2}{*}{$\begin{array}{c}\left.\begin{array}{c}\mathrm{sp} \\
(\mathrm{c} / \mathrm{min} \\
/ g\end{array}\right) \\
12725\end{array}$} & \multirow{2}{*}{$\begin{array}{c}\text { Valor L } \\
\begin{array}{c}\text { (mg P/ } \\
\text { vaso) }\end{array} \\
20,66\end{array}$} \\
\hline 1) $P_{0}$ & & & & & & \\
\hline 2) $P_{0}$ & - Ureia50 & 4,04 & 0,208 & 7,67 & 11198 & 24,33 \\
\hline 3) $P_{0}$ & - Ureia100 & 4,97 & 0,178 & 8,28 & 10645 & 25,66 \\
\hline 4) $P_{0}$ & - sulfato am.0 & 3.53 & 0,213 & 6,78 & 11978 & 22,66 \\
\hline 5) $P_{0}$ & - sulfato am.50 & 5,31 & 0,167 & 8,36 & 11678 & 23,33 \\
\hline 6) $P_{0}$ & - sulfato am. 100 & 5,71 & 0,176 & 9,54 & 10727 & 25,00 \\
\hline 7) $P_{22}$ & - Uréia & 4,72 & 0,390 & 17,82 & 7886 & 15,33 \\
\hline 8) $P_{22}$ & - Uréia 50 & 6,07 & 0,314 & 18,51 & 8176 & 14,00 \\
\hline 9) $P_{22}$ & - Uréia100 & 7,65 & 0,270 & 20,16 & 8001 & 14,33 \\
\hline 10) $P_{22}$ & - sulfato am. 0 & 5,34 & 0,342 & 17,75 & 7700 & 16,33 \\
\hline 11) $P_{22}$ & - sulfato am.50 & 6,26 & 0,295 & 17,97 & 8088 & 14,66 \\
\hline 12) $P_{22}$ & - sulfato am. 100 & 6,99 & 0,303 & 20,69 & 7305 & 18,66 \\
\hline 13) $P_{220}$ & - Uréiano & 4,67 & 0,854 & 39,43 & 1258 & 12,00 \\
\hline 14) $P_{220}$ & - Uréiaso & 6,34 & 0,779 & 48,73 & 1233 & 16,00 \\
\hline 15) $P_{220}$ & - Uréia 100 & 6,63 & 0,954 & 63,15 & 1269 & 13,00 \\
\hline 16) $P_{220}$ & - sulfato am.0 & 4,65 & 0,929 & 42,81 & 1225 & 16,33 \\
\hline 17) $P_{220}$ & - sulfato am.50 & 5,69 & 1,001 & 59,61 & 1246 & 14,00 \\
\hline 18) $P_{220}$ & - sulfato am.100 & 6,25 & 1,302 & 79,82 & 1249 & 12,66 \\
\hline d.m.s. (T & Tukey 58$)$ & 1,82 & & 11,65 & & 5,78 \\
\hline$C . V . \%$ & & 10,84 & & 13,77 & & 10,60 \\
\hline
\end{tabular}


lo arroz pode ser atribuida ao cátion $\mathrm{NH}_{4}$ Ou ao ànion $\mathrm{SO}_{4}$. Mu i tos pesquisadores, porēm, tem achado efeitos sinërgicos docátion NH4 na absorção de P (RENNIE e SPRATT, 1962; ESSAFFI et a) i i, 1962 e CALDWELL e BLANCHAR, 1965). Por sua vez, IAEA (1970) encontrou efeitos quase insignificantes do sulfato de amónio, aumentando ou diminuindo a absorção de $P$, dependendo do método de colocação do superfosfato no solo.

As porcentagens de $P$ aumentaram com os incrementos no carregador. Foram um pouco mais altos nos tratamentos sem $N$ e muito maiores nos tratamentos com 220 ppm de $P$ on de atingiram niveis de 1.3\%. As atividades especificas desceram com o incremento no carregador.

o valor 'L', de maneira geral, diminuiu com o aumento na dose de P (Fig. 3a). Houve diferença significativa entre $P_{0}$ e $P_{22}$ e a diferença entre $P_{22}$ e P220 dependeu do nivel de N. Não houve diferença entre as doses nem entre fontes de $N$. Houve incremento, não significativo, nos valores 'L' na dose de $P_{0}$ (livre de carregador) com as doses de nitrogênio, mas este efeito cessou quando o nivel de p foi 22 ou 220 ppm. os valores 'L' foram significativamente diferentes em todos os niveis de $P$ quando a fonte foi o sulfato de amónio na dose de $100 \mathrm{~kg} \mathrm{~N} / \mathrm{ha}$. Este fato pode estar relacionado com as altas porcentagens de $P$ nas plantas tratadas com sulfatode amónio, cujo efeito jà foi mencionado. 


\subsubsection{No Latossolo}

A anälise de variància dos resultados, mostrou serem significativos ao nivel de $1 \%$ os efeitos de niveis de , doses de $N$ e da interação $P X N$ sobre as produçōes de M.V.S. e de P total. Igualmente, niveis de $P$, fontes de $N$ e as interações $P X N$ e $P$ X sobre os valores 'L' (Veja-se apêndice 2 e 5).

De acordo com a tabela 5, a produção de M.V.S. aumentou comos niveis de P e de $N$. Houve diferença significativa entre os niveis de $P$, com exceção dos tratamentos com 22 e 220 ppm de $P$ sem N. Houve diferenças na produção de M.V.S. entre as doses zero e $100 \mathrm{~kg}$ de $\mathrm{N}$; entre as doses de zero e $50 \mathrm{~kg}$ de N-sulfato de Am e entre 50 e $100 \mathrm{~kg}$ de $N$-Uréia no nível de 220 ppm de P.

Porēm, as quantidades de M.V.S. foram inferiores neste solo às do podzölico nos niveis $P_{0}$ e $P_{22}$, embora fossem maiores quando o nivel de P foi 220 ppm. No Latossolo houve um aumento contínuo da produção de M.V.S., enquanto que no Podzölico diminuiu quando o nivel de carregador foi o māxi mo usado.

Com a exceção jā citada, o sulfato de Amônio deu maiores produções de M.V.S. Resultados semelhantes tem si do relatados por IAEA $(1970,1978)$, que atribuiram o efeito ao sulfato de Am o qual promove mais rapidamente o desenvolvimen to foliar. 
Tabela 5. Ensaio 2. Quantidade de Material Vegetal seco (MVS), porcentagem de fósforo (\%P), fósforo total, atividade especifica (sp) e valor 'L' no latossolo.

\begin{tabular}{|c|c|c|c|c|c|c|c|}
\hline \multicolumn{2}{|c|}{ TRATAMENTO } & & \multirow[b]{2}{*}{$\begin{array}{l}\text { MVS } \\
\text { (g/ } \\
\text { vaso) }\end{array}$} & \multirow[b]{2}{*}{$\% P$} & \multirow[b]{2}{*}{$\begin{array}{c}p \text {-total } \\
(\mathrm{mg} / \\
\text { vaso) }\end{array}$} & \multirow[b]{2}{*}{$\begin{array}{c}s p \\
(\mathrm{c} / \mathrm{min} \\
/ g)\end{array}$} & \multirow[b]{2}{*}{$\begin{array}{c}\text { Valor L } \\
\text { (mg/ } \\
\text { vaso) }\end{array}$} \\
\hline $\begin{array}{l}\text { Nível de } \\
\text { carre- } \\
\text { gador }\end{array}$ & $\begin{array}{c}\text { Fonte e } \\
\text { dose de } \\
\mathrm{N}\end{array}$ & & & & & & \\
\hline 1) $P_{0}$ & - Uréia 0 & & 3,20 & 0,100 & 2,71 & 3765 & 72,00 \\
\hline 2) $P_{0}$ & - Uréia 50 & & 3,33 & 0,099 & 2,81 & 3882 & 70,33 \\
\hline 3) $P_{0}$ & - Uréialoo & & 3,35 & 0,096 & 2,82 & 3831 & 72,66 \\
\hline 4) $P_{0}$ & - sulfato am. & 0 & 2,58 & 0,089 & 1,80 & 4212 & 64,33 \\
\hline 5) $P_{0}$ & - sulfato am. & 50 & 3,28 & 0,091 & 2,50 & 3868 & 70,00 \\
\hline 6) $P_{0}$ & - sulfato am. & 100 & 3,77 & 0,098 & 3,22 & 4268 & 64,00 \\
\hline 7) $P_{22}$ & - Uréia 0 & & 4,54 & 0,168 & 7,22 & 8583 & 13,00 \\
\hline 8) $P_{22}$ & - Uréia 50 & & 5,35 & 0,164 & 8,28 & 10273 & 6,66 \\
\hline 9) $P_{22}$ & - Uréia 100 & & 5,81 & 0,145 & 7,9 & 7712 & 17,00 \\
\hline 10) $P_{22}$ & - sulfato am. & 0 & 4,88 & 0,176 & 8,08 & 8110 & 15,00 \\
\hline 11) $P_{22}$ & - sulfato am. & 50 & 5,27 & 0,155 & 7,70 & 97.18 & 8,66 \\
\hline 12) $P_{22}$ & - sulfato am. & 100 & 5,94 & 0,136 & 7,56 & 7609 & 17,00 \\
\hline 13) $P_{220}$ & - Uréia 0 & & 5,50 & 0,300 & 16,01 & 1182 & 30,33 \\
\hline 14) $P_{220}$ & - Uréia 50 & & 6,49 & 0,248 & 15,70 & 1206 & 25,33 \\
\hline 15) $P_{220}$ & - Uréia 100 & & 8,02 & 0,280 & 21,78 & 1187 & 29,33 \\
\hline 16) $P_{220}$ & - sulfato am. & 0 & 5,81 & 0,303 & 17,11 & 1184 & 34,00 \\
\hline 17) $P_{220}$ & - sulfato am. & 50 & 7,62 & 0,291 & 21,67 & 1063 & 58,33 \\
\hline 18) $P_{220}$ & - sulfato am. & 100 & 8,08 & 0,259 & 20,42 & 1138 & 40,00 \\
\hline d.m.s. (T & Tukey 5\%) & & 1,42 & & 3,65 & & 15,84 \\
\hline C.V. 若 & & & 8,98 & & 12,17 & & 13,07 \\
\hline
\end{tabular}


Na tabela 5, observa-se que os teores de P total aumentaram significativamente com o incremento nos níveis de carregador. Não houve efeito das doses nem das fontes do $N$ nos níveis de zero e 22 ppm de P. Houve, porém, efeito das do ses de $50 \mathrm{~kg}$ de N-sulfato de Am e de $100 \mathrm{~kg}$ de N-Urëia no nível somente de $220 \mathrm{ppm}$ de P. Neste caso as quantidades de P total absorvido pelo arroz foram significativamente menores que as absorvidas pela mesma cultura no solo podzolizado.

As porcentagens de P na planta de arroz (Tabela 5), aumentaram com os níveis de carregador, sendo baixos nos níveis zero e 22 ppm de P e mëdios no nível de 220 ppm. Ao conträrio do solo podzolizado, neste solo houve menor absorção de P com a adição de 220 ppm de P. isso mostra que no latossolo, o foi menos disponivel para as plantas devido provavelmente a fixação deste elemento.

$$
\text { Segundo BITTENCOURT e ZAMBELLO (1975), O latos }
$$
solo por conter alta porcentagem de argila, ë considerado de alto poder de fixação de fosfato, enquanto o Podzolizado é t do como capaz de reter apenas baixas quantidades.

As atividades especificas mostraram uma tendē cia diferente que no solo PVA: enquanto foram similares nos niveis de 22 e 220 ppm de P, foram muito menores quando nãohouve carregador devido possivelmente a adsorção de 32 pelo solo.

De acordo com os dados da tabela 5 , os valores 'L' variaram significativamente em forma hiperbölica (Fig. 3 b) com o incremento nos niveis de carregador, tendo um ponto de 
minimo no nível de 22 ppm de $P$. Não houve efeito da dose nem da fonte de $N$ nos niveis zero e 22 ppm de P. Houve efeito de sulfato de Am nas trés doses de $N$ somente no nível de 220 ppm de P. Segundo Larsen, 1957 citado por MATTINGLY (1957), a fon te de N afetou a produção de M.V.S. e a absorção de P, mas não alterou o fósforo lábil do solo.

\section{3. TERCEIRO ENSAIO}

Avaliação do efeito de cinco níveis de carregador no valor 'L' usando o solo podzolizado e o arroz como planta indicadora.

A anālise de variància de acordo com PIMENTEL GOMES (1978) ao nivel de $1 \%$ de probabilidade, revelou efeitos significativos dos tratamentos na produção de M.V.S., p total em plantas e valor 'L'.

Segundo a tabela 6 , a produção de M.V.S., o teor de P total e o valor 'L' aumentaram com o incremento nos niveis de carregador. Porém, houve efeito significativo somente dos niveis de $P$ iguais ou maiores de 33 ppm sobre a pro dução de M.V.S. e os teores de P total; porém, ao igual que no ensiaio 2 as produçōes de M.V.S. diminuiram com os níveis muito altos de $P$, neste caso 99 ppm. Com relação ao valor 'L' somente o nivel de 99 ppm de $P$ causou efeito significativo se gundo o teste de Tukey a $5 \%$ (Fig. 4).

Resultados semelhantes tem sido reportados por 


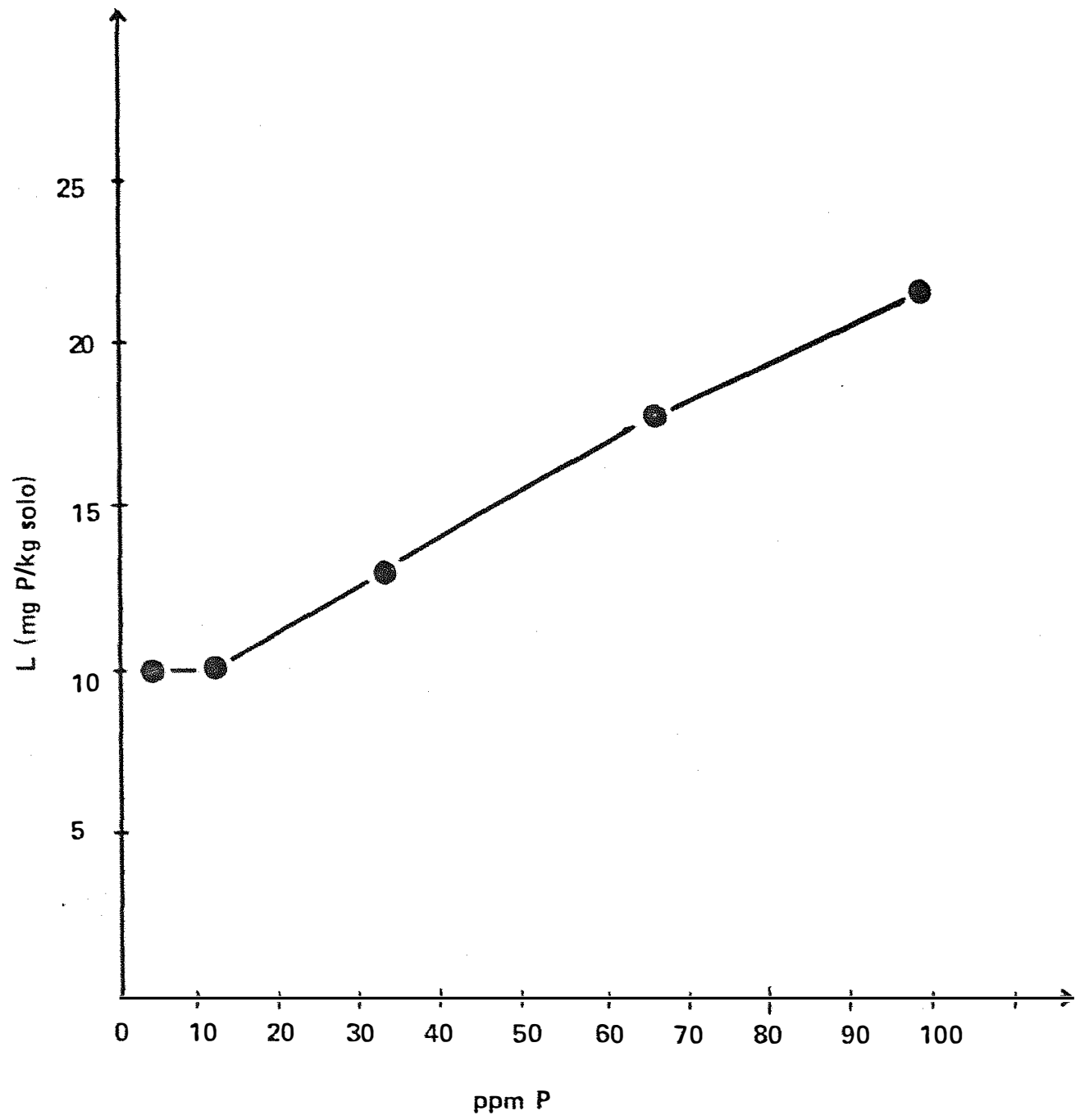

Figura 4. Valor 'L' em função dos niveis de carregador no solo podzolizado. 
MARAIS et alii (1969) que encontraram que o incremento no nivel de carregador até determinado ponto não afetou ovalor 'L', mas houve diferenças marcadas na produção de matéria seca e na absorção de $P$ pelas plantas. Elo et aliî (1965) relataram aumento do M.V.S. e da absorção de P com incremento na dose de P apl cado. MEKHAEL et alii (1965) encontraram aumentos contínuos no teor de P nas plantas, mas a produção de matéria seca só respondeu a dose de $20 \mathrm{ppm}$ de $P$.

Por outro lado, os incrementos nos niveis de carregador causaram aumentos nas porcentagéns de fósforo encontrado nas plantas até niveis considerados muito altos (0.649) e que provavelmente afetaram a produção de M.V.S. As atividades especificas diminuiram com o aumento dos niveis de carregador.

\subsection{QUARTO ENSAIO}

Avaliação do efeito de très níveis de $P$ e duas espēcies de plantas (feijoeiro e arroz), cultivadas em condiçöes de sequeiro e submersão, em dois solos sobre o valor 'L'.

Neste ensaio apenas o arroz foi cultivado em condições de submersão.

\subsubsection{Efeito dos níveis de $P$ nas duas culturas em condiçōes de sequeiro}

Segundo a anälise de variância dos resultados, 
Tabela 6. Ensaio 3. Quantidadf. de material vegetal seco (MVS), porcentagem de fósforo (\%P), fósforo total, ativida de especifica (sp) e valor 'L' dos tratamentos

\begin{tabular}{|c|c|c|c|c|c|}
\hline Tratamento & $\begin{array}{l}\text { M.V.S. } \\
\text { (g/vaso) }\end{array}$ & $\% P$ & $\begin{array}{c}\text { P-total } \\
\text { (mg/vaso) }\end{array}$ & $\begin{array}{l}\mathrm{sp} \\
(\mathrm{c} / \mathrm{min} / \mathrm{g})\end{array}$ & $\begin{array}{l}\text { Valor L } \\
\text { (mg P/kg } \\
\text { solo }\end{array}$ \\
\hline 1) $5,5 \mathrm{ppm}$ de $P$ & 4,59 & 0,227 & 9,94 & 23935 & 10 \\
\hline 2) $11 p p m$ de $P$ & 4,94 & 0,273 & 13,00 & 17324 & 10 \\
\hline 3) $33 \mathrm{ppm} d \mathrm{e} P$ & 5,24 & 0,440 & 23,19 & 8053 & 13 \\
\hline 4) $66 \mathrm{ppm}$ de $p$ & 5,31 & 0,547 & 28,62 & 4447 & 18 \\
\hline 5) $99 \cdot p p m$ de $p$ & 4,83 & 0,649 & 30,92 & 3098 & 22 \\
\hline$F$ & $8,00 * *$ & & $83,24 * \star$ & & $7,52 * \star$ \\
\hline d.m.s. (Tukey 5\%) & 0,49 & & 4,75 & & 8,55 \\
\hline C.V. \% & 3,65 & & 8,37 & & 21,51 \\
\hline Atividade do padrão: & 373 & $820 \mathrm{c} / \mathrm{m}$ & & & \\
\hline
\end{tabular}


houve efeito significativo ao nivel de $1 \%$ dos níveis de $P$, do tipo de solo, da espécie de planta ou cultura e da interação solo por cultura $S \times C$ sobre os parámetros analisados: produção de M.V.S., teor de P total e valor 'L'. Houve efeito significativo igualmente da interação niveis de fósforo por solo PxS sobre os teores de $P$ total e da interação níveis de fósfo ro por espécie de planta ou cultura PxC sobre o valor 'L' (veja no apêndice 3 e 6).

Observa-se na tabela 7 , que as produções de M. V.S. aumentaram com o nivel de carregador, sendomaiores no solo P.V.A. que no L.E. e maiores para o feijoeiro do que para arroz. Foi diferente entre as culturas em todos os níveis de P no solo L.E. Embora o latossolo apresente mais alto teor de fósforo solüvel $\left(\mathrm{H}_{2} \mathrm{SO}_{4} 0.05 \mathrm{~N}\right)$ e soma de bases maior que 5 emg/lo0g, as produções de M.V.S. foram menores que no so lo podzolizado.

Na tabela 7, nota-se que os teores de P total incrementaram-se com os niveis de carregador sendo muito maio res para o arroz do que para o feijoeiro no solo podzolizado. Houve diferença significativa entre as duas culturas em todos os niveis de $P$ e entre os niveis 0.1 e 10 ppm para as duas culturas no solo podzolizado. Acredita-se que o "carregador" de P da raiz do arroz é mais eficiente do que aquele do feijoeiro (MALAVOLTA, 1980).

Para RUSSELL (1963) as plantas em solos basálticos absorveram diferentes quantidades de fosfato. Por exem- 
Tabela 7. Ensaio 4. Quantidade de material vegetal seco (M.V.S.), porcentagem de fösforo (\%P), fösforo total, atividade especifica (sp) e valor ' $L$ ' dos tratamentos, nos solos PVA e LE

TRATAMENTO

\begin{tabular}{|c|c|c|c|c|c|c|c|}
\hline Solo & Cultura & $\begin{array}{l}\text { Nível de } \\
\text { Carregador }\end{array}$ & $\begin{array}{l}\text { MVS } \\
\text { (g/ } \\
\text { vaso) } \\
\end{array}$ & $\% P$ & $\begin{array}{c}p \text {-total } \\
\text { (mg/ } \\
\text { vaso) }\end{array}$ & $\begin{array}{c}\mathrm{sp} \\
(\mathrm{c} / \mathrm{min} \\
/ \mathrm{g}) \\
\end{array}$ & $\begin{array}{l}\text { Valor L } \\
\text { (mg P/ } \\
\mathrm{kg} \mathrm{sollo)} \\
\end{array}$ \\
\hline 1) PVA & - Arroz & $P_{0.1}$ & 2,20 & 0,220 & 4,36 & 14783 & 16,66 \\
\hline 2) PVA & - Arroz & $P_{5}$ & 2,91 & 0,191 & 5,09 & 11057 & 11,33 \\
\hline 3) PVA & - Arroz & $P_{10}$ & 2,91 & 0,265 & 7,24 & 8913 & 10,33 \\
\hline 4) PVA & - Feijão & $P_{0.1}$ & 2,29 & 0,103 & 1,72 & 4372 & 57,33 \\
\hline 5) PVA & - Feijão & $P_{5}$ & 2,64 & 0,126 & 2,69 & 5165 & 30,33 \\
\hline 6) PVA & - Feijão & $P_{10}$ & 3,52 & 0,119 & 3,57 & 5650 & 22,33 \\
\hline 7) $L E$ & - Arroz & $P_{0.1}$ & 1,43 & 0,112 & 1,10 & 5915 & 31,00 \\
\hline 8) LE & - Arroz & $P_{5}$ & 1,63 & 0,132 & 1,66 & 7130 & 20,33 \\
\hline 9) LE - & - Arroz & $P_{10}$ & 1,95 & 0,140 & 2,23 & 5492 & 23,00 \\
\hline 10) LE - & - Feijão & $P_{0.1}$ & 2,59 & 0,098 & 1,84 & 1208 & 150,33 \\
\hline 11) LE - & - Fe ijão & $P_{5}$ & 2,98 & 0,099 & 2,35 & 1823 & 97,00 \\
\hline 12) LE - & - Feijão & $P_{10}$ & 2,81 & 0,099 & 2,14 & 1647 & 101,66 \\
\hline d.m.s. & (Tukey & $5 \%)$ & 0,66 & & 1,37 & & 21,37 \\
\hline C.V. $\%$ & & & 8,92 & & 15,41 & & 15,08 \\
\hline
\end{tabular}


plo, o azevem absorvou 5 vezes mais $P$ do que a cevada nos pri meiros 28 dias, mas logo os valores foram similares (56 dias). Segundo ZELLER (1963) em certos solos, diferentes plantas podem absorver diferentes frações de seu fósforo requerido e is so significa que as plantas tēm diferentes capacidades deabsor ver nutrientes (feeding power); essa capacidade das plantas vai ser diferente em diferentes solos. Algumas propriedades das plantas podem influenciar sua habilidade de absorção, tais co mo: a) diferente mecanismo de absorção; b) sistema radicular de diferente tamanho; c) diferentes excreçöes radiculares; d) diferentes reservas de nutrientes nas sementes.

Para NEPTUNe (1963), a espécie vegetal deveser tomada em consideração principalinente em experimentos de curta duração e quando um solo com baixo teor de fosfato é util i $z$ ado

As porcentagens de $P$ foram maiores nas plantas no solo podzolizado e ao igual que no primeiro ensaio foram mais altos para arroz do que para o feijoeiro. As atividades especificas foram maiores para o arroz do que para o feijoeiro nos dois solos e não tiveram uma tendéncia definida.

Na tabela 7, observa-se que os valores 'L' decresceram significativamente nos dois solos quando o nivel de carregador aumentou de 0.1 para 5 ppm (Fig. 5a). Foram diferentes entre as duas culturas em todos os níveis de $P$ no solo L.E. e no nivel de 0.l ppm de P no solo podzolizado; entre os niveis 0.1 e 5 ppm de p nos dois solos para o feijoei- 


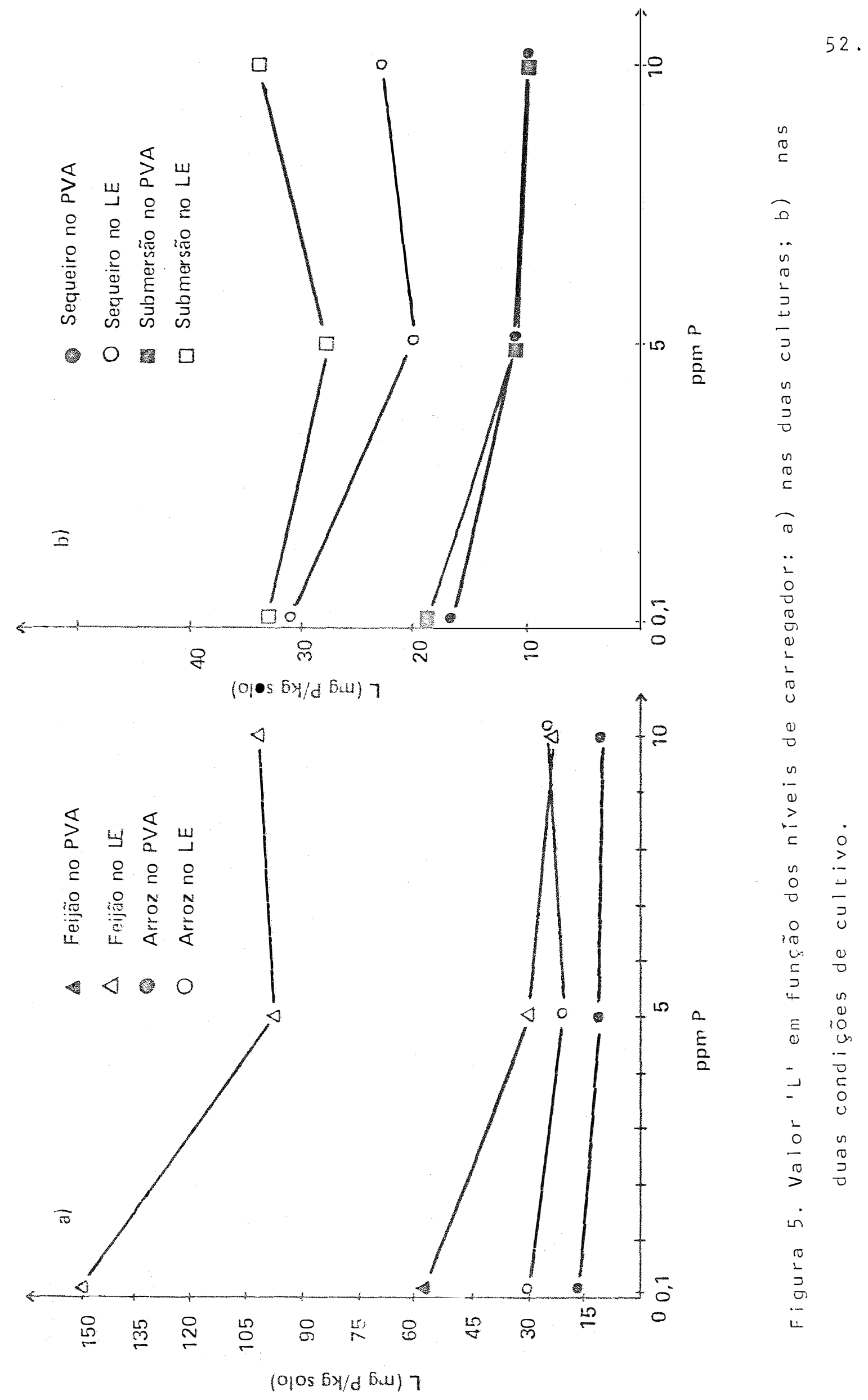


ro. Näo houve diferença entre os valores 'L' obtidos com 5 e 10 ppm de carregador.

\subsubsection{Efeito dos níveis de P no arroz cultivado na condição de submersão}

A anălise de variància dos resultados, mostrou efeito significativo ao nivel de $1 \%$ dos niveis de $p$, do tipo de solo, das condiçōes e da interação solo por umidade ou con dição de cultivo SxU sobre os três paràmetroś analisados: pro dução de M.V.S., P total e valor 'L'. Tambëm houve efeito das interações $P \times S$ e $P \times S \times U$ sobre o valor 'L' (veja-se no apēndice 3 e 6).

A produção de M.V.S. aumentou com o incremento no carregador (Tabela 8) e foi maior na condição de submersāo em todos os casos. Foi diferente entre as duas condiçōes de cultivo em todos os níveis de p para o solo L. E. e nos níveis 0.1 e 10 ppm no solo podzolizado; entre os níveis lo ppm de p e os outros dois na condição de submersāo e entre 0.l ppm de P e os outros na condição de sequeiro no solo podzolizado; e entre os niveis 10 ppm e os outros na condição de sequeiro no Latossolo. Os níveis de p nāo causaram nenhum efeito sobre a produçāo de M.V.S. no Latossolo na condiçāo de submersão.

Na tabela 8, observa-se que os teores de $P$ a $\underline{u}$

mentaram com o incremento no nivel de carregador, sendo sempre maiores na condição de submersão. Os teores de P total fo- 
Tabela 8. Ensaio 4. Quantidade de Material Vegetal seco (MVS), porcentagem de fósforo (\%P), fósforo total, atividä de específica (sp) e valor 'L' dos tratamentos nos Solos PVA e LE

\section{TRATAMENTO}

\begin{tabular}{|c|c|c|c|c|c|c|c|}
\hline Solo & $\begin{array}{l}\text { Condição } \\
\text { de cultivo }\end{array}$ & $\begin{array}{c}\text { Nível de } \\
\text { carre- } \\
\text { gador }\end{array}$ & $\begin{array}{c}\text { MVS } \\
\text { (g/ } \\
\text { vaso) }\end{array}$ & $\% P$ & $\begin{array}{c}P \text {-total } \\
(\mathrm{mg} / \\
\text { vaso) }\end{array}$ & $\begin{array}{c}s p \\
(c / m i n \\
/ g)\end{array}$ & $\begin{array}{c}\text { Valor L } \\
\text { (mg P/kg } \\
\text { solo) }\end{array}$ \\
\hline 1) PVA & - submersão & $P_{0.1}$ & 3,13 & 0,227 & 6,63 & . 13493 & 18,66 \\
\hline 2) PVA & - submersão & $P_{5}$ & 3,39 & 0,236 & 7,50 & 11295 & 11,00 \\
\hline 3) PVA & - submersão & $P_{10}$ & 3,65 & 0,250 & 8,33 & 9163 & 10,33 \\
\hline 4) PVA & - seque iro & $P_{0.1}$ & 2,20 & 0,220 & 4,36 & 14783 & 16,66 \\
\hline 5) PVA & - sequeiro & $P_{5}$ & 2,91 & 0,191 & 5,09 & 11057 & 11,00 \\
\hline 6) PVA & - sequeiro & $P_{10}$ & 2,91 & 0,265 & 7,24 & 8913 & 10,33 \\
\hline 7) $L E$ & - submersão & $P_{0.1}$ & 2,58 & 0,175 & 4,00 & 5588 & 32,66 \\
\hline 8) $L E$ & - submersão & $P_{5}$ & 2,65 & 0,201 & 4,83 & 5597 & 27,66 \\
\hline 9) $L E$ & - submersão & $P_{10}$ & 2,99 & 0,206 & 5,67 & 4110 & 34,33 \\
\hline 10) LE & - seque iro & $P_{0.1}$ & 1,43 & 0,112 & 1,10 & 5915 & 31,00 \\
\hline 11) LE & - sequeiro & $P_{5}$ & 1,63 & 0,132 & 1,66 & 7130 & 20,33 \\
\hline 12) LE & - sequeiro & $P_{10}$ & 1,95 & 0,140 & 2,23 & 5492 & 23,00 \\
\hline d.m.s. & (Tukey 5\%) & & 0,48 & & 1,88 & & 5,19 \\
\hline C.V. & & & 6,15 & & 12,94 & & 8,47 \\
\hline
\end{tabular}


ram diferentes entre as duas condições de cultivo nos dois so los e em todos os níveis de P, com exceção do nivel de lo ppm de $P$ no P.V.A. Foram diferentes entre os niveis 0.1 e 10 ppm de P no P.V.A. na condição de sequeiro.

Segundo SALAM e HASHISH (1962) o aumento da absorção de ${ }^{32}$ p quando a umidade se aproxima à umidade equiva lente é provavelmente devido à liberação de $P$ do solo presumivelmente fixado em menores niveis de umidade. Para LARSEN (1967) a condição de submersão dos solos causa mobilizaçãodos fosfatos de ferro. Para OLSEN et alii (1948; 1961), há maior absorção de $P$ do adubo em solos em condições de submersão. Pạ ra PONNAMPERUMA (1977) nas condições de submersão aumentaa dis ponibilidade de alguns nutrientes entre eles o P.

os teores de $P$ total nas plantas, como as produções de M.V.S., foram significativamente menores no Latosso lo na condição de sequeiro, devido possivelmente a fixação do P adicionado pelo solo. Resultados semelhantes tem sido repor tados por muitos autores (MALEINA, 1958; MACHADOGRACI0, 196I; VOLK e MCLEAN, 1963 e NEPTUNE, 1964).

As porcentagens de $P$ foram mais altas na condição de submersão nos dois solos, principalmente no L.E. Aumentaram muito pouco com os niveis de carregador. As atividades especificas diminuiram com os niveis de $P$, foram maiores para o P.V.A. e foram semelhantes entre as duas condições de cultivo para cada solo.

De acordo com os dados da tabela 8, Fig. 5b,os 
valores 'L' diminuiram com o nivel de carregador nos dois solos, com exceção do solo L.E. na condição de submersão. Foram diferentes entre os niveis 0.1 ppm e os outros dois no P.V.A. e entre 5 e 10 ppm no L.E. sob submersão. Os valores 'L' foram diferentes entre as duas condições, de cultivo nos níveis de 5 e 10 ppm de P no Latossolo.

LARSEN (1969) relatou que as determinações do valor 'L' com arroz, indicam que em condições de submersão, o equilíbrio isotópico entre o 32 p adicionado e o fósforo lábil do solo foi atingido em 24 dias.

Fazendo uma avaliação conjunta dos quatro ensaios verifica-se que as produções de M.V.S. permaneceram cons tantes com baixos niveis de carregador, até 5 ppm. Houve um li geiro aumento no M.V.S. com o incremento nas doses de $N$, em ca da nivel de fósforo e um aumento maior com a época de colheita. As culturas no Latossolo deram sempre menor M.V.S. A condição de submersão causou incremento no M.V.S. nos dois solos.

os teores de fósforo total nas plantas não sofreram nenhum efeito do incremento nos niveis decarregadorme nores de $5 \mathrm{ppm}$. Aumentaram rapidamente com os incrementos maio res no carregador, principalmente, no solo podzolizado e maior ainda quando foi aplicado sulfato de amônio. Houve aumento dos teores de p total com as doses de nitrogénio, com a época de colheita e com a condição de submersão.

As porcentagens de $P$ nas plantas tiveram com- 
portamento semelhante aos teores de $P$ total nos dois solos. Apesar de serem solos com teores médios de P, as duas culturas, nas duas épocas, apresentaram niveis deficientes de P, com exceção do arroz no P.V.A. na época de 30 dias, quando baixos niveis de carregador foram aplicados.

$$
\text { Quando altos niveis de carregador foram adicio }
$$

nados, houve maior absorção de $P$ pelas plantas. 0 arroz no P.V.A. apresentou porcentagens de $P$ até de $1.3 \%$, consideranexcessivo enquanto, no L.E. estas não foram além de $0.3 \%$. Is so indica que o $P$ aplicado permaneceu mais disponivel noP.V.A. causando consumo de luxo por parte do arroz, enquando no L.E. foi fixado. De fato este solo apresenta teores mais altos de óxidos de ferro e de caulinita que o solo podzolizado.

Para AMER (1962) parte do P adicionado, no método livre de carregador, pode ser fixado por reações com com postos altamente fixadores de $P$ de modo que os produtos de rea ção não atinjam o equilibrio com a solução. 0 uso de carregador diminui as perdas, mas ao a umentar a quantidade de carregador, aumenta a quantidade de $P$ adsorvido pelo solo, afetando a velocidade de troca isotópica.

As atividades ( $32 p$ ) adicionadas aos vasos em ca da ensaio foram semelhantes independentemente do nível de car regador, dando diferente atividade especifica para cada trata mento. Nas plantas as atividades especificas foram diminuindo com o nivel de carregador. I guais resultados foram relatados por BAKER (1964). Porēm, no ensaio l, a tendência foicon- 
träria e as atividades específicas aumentaram com os incremen tos de carregador menores de 1.33 ppm.

- Os valores 'L' mudaram com os niveis de carregador, com a espécie vegetal e com a época de colheita. Foram afetados pela condição de submersão no Latossolo e foram independentes das doses e fontes de nitrogênio.

Em todos os casos, os valores ' $L$ ' foram mais altos quando determinados com muito baixos ou muito altos niveis de carregador, menores de $1.33 \mathrm{ppm}$ e maiores ou iguais a 33 ppm, respectivamente. Para AMER (1962) a determinação do valor 'L' sem carregador (carrier-free) superestima o P trocável. Três razões podem ser dadas: a) há uma lenta troca iso töpica do $32 \mathrm{p}$ livre de carregador com o p do solo (LARSEN e SUTTON, 1963); b) há adsorção do $32 p$ às paredes dos vidros e materiais usados para preparar e aplicar o p marcado (McAULIE FE et alii, 1948); c) o fösforo adicionado reage com o $P$ do solo para formar por exemplo fosfatos de alumínio que logo im pedem o equilibrio (LARSEN e GUNARY, 1964). Segundo SOKOLOV (1955) a dose de 31 p adicionada ao solo não deve ser muito a ! ta para evitar alguma influéncia do $P$ sobre o teor de $P$ dispo nivel do solo.

A determinação do valor ' $L$ ' dependeu da espécie vegetal utilizada. Resultados semelhantes tem sido relatados por NELSON et alii (1948), RUSSELL et alii (1955), NYE e FOSTER (1958), ANDERSEN et ali i (1961), BAKER (1964) e KALRA e SO PER (1968). Segundo RUSSELL (1963), este fato pode ser devido 
a que a atividade específica do fosfato (32p/31p) não foi totalmente constante na fração lábil do solo que as plantas absorveram. Para.ZELLER (1963), as plantas tem diferente capaci dade para absorver nutrientes, neste caso, o feijoeiro tem me nor capacidade de absorver $P$ que o arroz. Como os ensaios foram feitos em vasos, descarta-se a possibilidade de que seja devido a maior ou menor tamanho do sistema radicular.

Apesar que a anälise estatística tenha mostrado que a época de colheita não afetou o valor 'L', os valores obtidos na segunda colheita foram apreciavelmente diferente dependendo do tipo de cultura. E provável que o fato de se fạ zer anälise conjunta de duas culturas com amplas diferenças, faz com que o d.m.s. fosse alto demais para permitir observar efeito da época de colheita no arroz. Para LARSEN e SUTTON (1963) o aumento linear dos valores 'L' durante o período de crescimento pode ser devido a uma mobilização constantedo fós foro não lábil previamente, de acordo com o consumo de p pela cultura.

Quanto as doses e fontes de $N$, elas não causaram nenhum efeito sobre o valores 'L'. Embora o sulfato de amōnio tenha dado resultados diferentes no Latossolo, afetando a produção de M.V.S. e a absorção de $\bar{P}$.

A condição de submersão do solo estabilizou os valores 'L' no latossolo evitando o efeito dos niveis crescen tes de carregador, porém, aumentou o P disponível dos solos. Resultados semelhantes tem sido relatados por SHAPIRO e 
60.

ARMIGER (1958), OLSEN et alii (1961), LARSEN (1964, 1969) e PATNAIK et ali i (1979).

- De maneira geral, considera-se que o valor 'L' deve ser determinado utilizando-se niveis de p próximos ao p do solo (AMER, 1962). O fösforo extraido com H $\mathrm{S}_{4} 0,05 \mathrm{~N}$ acusou 11,6 ppm de p para o solo podzolizado e 13,9 ppm para o La tossolo. Neste trabalho obteve-se boa repetibilidade nos valores 'L' obtidos com niveis de carregador de 1.33 a $11 \mathrm{ppm}$ de P como carregador, no solo P.V.A.

Finalmente, segundo SCHEFFER e ULRICH (1958), sendo o solo um material heterogẽneo, não se pode esperar que o fósforo isotopicamente trocāvel, como um todo, seja uma medida exata do fósforo disponivel para as plantas. 


\section{CONCLUSÕES}

Com base nos resultados deste trabalho podemos concluir que:

1. Os valores 'L' foram mais altos quando foram utilizadosba xos niveis de carregador nos dois solos.

2. Os valores ' $L$ ' dependem da espēcie vegetal. Foram maiores para o feijoeiro do que para o arroz.

3. Os valores 'L' no Latossolo variaram com a época de colhe ta.

4. A dose e fonte de nitrogēnio não afetaramos valores 'L'. Porēm, o sulfato de amōnio causou um efeito sinērgico na absorção de $P$ quando a dose de carregador foi de 220 ppm no solo podzolizado. 
5. No Latossolo, a condição de submersão aumentou a produção de material vegetal seco e o teor de fósforototal, porém, os valores.' $L$ ' permaneceram constantes.

6. Os valores 'L' obtidos com niveis de carregador de 1.33 a 11 ppm de fósforo, com arroz aos 30 dias, foram semelhantes aos obtidos com $\mathrm{H}_{2} \mathrm{SO}_{4} 0.05 \mathrm{~N}$ no solo Podzolizado. No Latossolo foram completamente diferentes.

$$
\begin{aligned}
& \text { Em vista da variabilidade encontrada } \\
& \text { nos valores 'L', julgamos que esta } \\
& \text { técnica näo pode ser considerada ade } \\
& \text { quada para aconselhar os agricultores } \\
& \text { a respeito das necessidades em fósfo } \\
& \text { ro de seu solo. E preciso continuar } \\
& \text { com as pesquisas nesse sentido a fim } \\
& \text { de estabelecer os parametros que per } \\
& \text { mitam a universalidade do valor 'L'. }
\end{aligned}
$$


ABDEL SALAM, M.A.; S.A. SABET e S. HASHISH, 1964. Patterns of fixation of 32 -Labelled phosphate by some soil minerals. Plant and Soil. The Hague, $x \times 2: 241-249$.

ALOISI; R.R.; G. RANZANI, J.L.I. DEMATTE E C.C. CERRI. 1975. Mineralogia da fração argila de alguns solos do município de Jaboticabal, S.P. Anais do XV Congresso Brasileiro de Ciència do solo. Campinas, 457-460.

AMER, F.; S. MAHDI, e A. ALRADI, 1969. Limitations in isotopic measurements of labile phosphate in soils. J. Soil Sci. Ox ford $x x$ : $91-99$.

ANDERSEN, A.J.; B. GREGERS-HANSEN e G. NIELSEN, 1961. Determination of the phosphate condition of soils by means of 
Radioactive phosphorus in pot experiments. Acta Agric. Scand. Stockholm, X1: $270-290$.

ANDERSEN, A.J. e J.D. THOMSEN, 1979. Efficiency in absorption and utilization of phosphorus of four plant species. In: IAEA-ISotopes and Radiation in Research on soil-plant Relationships. Viena 499-512.

BAKER, D.E., 1964. A study of isotopic dilution as a method for relating phosphorus retention to availability of Phosphorus in widely diffent soils. Soild Sci. Soc. Am. J. Madison, 28: $511-516$.

BITTENCOURT, V.C. e E. ZAMBELLO, 1975. Comportamento do fösforo em solos tropicais. I. lsotermas de adsorção. Pesq. agropec. bras., sér. Agron., Embrapa Brasilia 10: 59-64.

CALDWELL, A.C. e R.W. BLANCHAR, 1965. Phosphorus uptake by plants and ion concentrations in fertilizer zones as affec ted by ammonium, potassium and dilution. In: IAEA. I sotopes and radiation in soil-plant nutrition studies. Viena, 413$-424$.

CALZADA, B.J., 1964. Métodos estadisticos para la investigaciōn. 2a. ed, Lima, Distribuidor J. Calzada, B., 494 p. 
CARMELLO, C.Q.A., 1980. Fatores que afetam a determinação do valor 'L' e sua comparação com a capacidade de adsorção de fósforo e o valor 'E' em dois solos doEstadode São Paulo. Piracicaba, ESALQ/USP, 72p. (dissertação de mestrado).

CATANI, R.A.; J.R. GALLO e H. GARGANTINI, 1955. Amostragem do solo, métodos de anälise, interpretação e indicações gerais para fins de fertilidade. Boletim, IAC-CAMPINAS, n:69, $29 p$.

CHASE, E.D. E J.L. RABINOWITS, 1967. Radioisotopes in chemistry. Principes of radioisotopes metodology. Minneapolis, Burgess Publishing, p. $420-423$.

DALAL, R.C. e E.G. HALLSWORTH, 1977. Measurement of isotopic exchangeable soil phosphorus and interrelationship among parameters of quantity, intensity and capacity factors. Soil Sci. Amer. J., Chicago, 41: $541-546$.

DEAN; L.A.; W.L. NELSON; A.J. MaCKENZIE; W.H.ARMIGER E W.L. HILL, 1948. Application of tracer technique to studies of phosphatic fertilizer utilization by crops: 1. Greenhouse experiments. Soil. Sci. Soc. Amer. Proc., Madison, 12:107112

EID, M.T.; M.F. HADIDI; Y. BARRADA E M.J. SHAWARBI, 1965. Study 
of phosphorus uptake on soils of the United Arab Republic. In: IAEA. Isotopes and Radiation in soil-plant nutrition studies. Viena, 590-599.

ENSMINGER, L.E. e R.W. PEARSON, 1957. Uses of macronutrient Isotopes in soil fertility research. In Atomic Energy and Agriculture Washington, D.C., American Association of Advan cement of Science Publ., Washington D.C., 49: 1-18.

ESSAFI, A.; J. CLINE e A. MATHIEU, 1962. Utilization du phosphore-32 dans l'étude de l'assimilation par la plant de l'acide phosphorique selon sa localisation dans le sol et selon son association ou non à l'Azote. In: IAEA Radioisotopes in soil-plant nutrition studies. Viena, 443-452.

FRIED, M. e L.A. DEAN, 1952. A concept concerning the measure ment of available soils nutrients. Soil Sci. Baltimore 73: $263-271$

GRUNES, D.L.; H.J. HAAS E S.H. SHIH, 1955. Effect of LOng-time dryland cropping on available phosphorus of cheyenne fine sandy loam. Soil science. Baltimore, 80: 127-137.

GUNARY, D. e C.D. SUTTON, 1967. Soil-factors affecting plant uptake of phosphate. J. Soil Sci. Oxford, 18: 167-173. 
HENDRICKS, S.B. e L.A. DEAN, 1948. Basic concepts of soil and fertilizer studies with radioactive phosphorus. Soil Science Soc. Amer. Proc. (1947) Madison, 12:98-100.

INTERNATIONAL ATOMIC ENERGy AgEnCy, 1970. Rice Fertilization. (Technical Reports Series n? 108). Viena, $177 p$.

INTERNATIONAL ATOMIC ENERGY AGENCY, 1976. Measurement of soil and fertilizer phosphorus availability to plants. In: Tracer manual on crops and soils. (Technical'Reports Series n? 171). Viena, 129-137.

INTERNATIONAL ATOMIC ENERGY AGENCY, 1978. I sotope studies on rice fertilization (Technical reports series n? 181 ), Viena, $134 p$

KALRA, Y.P. e R.J. SOPER, 1968. Efficiency of rape, oats, soy beans and flax in absorption soil and fertilizer phosphorus at seven stages of growth. Agronomy J., Madison, 60: 209212.

KILMER, V.J. e L.T. ALEXANDER , 1949. Methods of making mechanical analysis of soils. Soil Sci., Baltimore, 68: 15-26.

LAMM, C.G., 1962. Factors affecting the ratio in the plants of a nutrient derived from the fertilizer and the soil. 
In: IAEA Radioisotopes in soil-plant nutrition studies, Viena, 343-352.

LARSEN, S., 1952. The use of $32 p$ in studies on the uptake of phosphorus by plants. Plant and Soil. The Hague, IV: 1-I0.

LARSEN, S. e 1.J. COOKE, 1961. The influence of radioactive phosphate level on the absorption of phosphate by plants and on the determination of labile soil phosphate. Plant and Soil. The Hague, xiv: $43-47$.

LARSEN, S. E C.D. SUTTON, 1963. The influence of soil volume on the absorption of soil phosphorus by plants and on the determination of labile soil phosphorus. Plant and Soil. The Hague, xviii 1: $77-84$.

LARSEN, S., 1964. On the relationship between labile and non labile phosphate in soils. Act Agr. Scand. Stockholm, 14: $249-253$.

LARSEN, S. e D. GUNARY, 1964. The determination of labile soil phosphate as influenced by the time of application of labe led phosphate. Plant and Soil. The Hague, $x \mathbf{x}, 2: 135-142$.

LARSEN, S., 1967. Isoionic exchange of phosphate in paddy Soils. Plant and Soil. The Hague, xxvii, 3: 401-407. 
LARSEN, S., 1969. L value determination under paddy soil conditions. Plant and Soil. The Hague, $x \times x i, 2: 282-286$.

LOTT, W.L.; J.P. NERY; J.R. GALLO; J.C. MEdCALF, 1956. A técnica da análise foliar aplicada ao cafeeiro. Campinas, Ins tituto Agronōmico, 29p. (Boletim 79).

MACHADO GRACIO, J.T., 1961. Phosphorus fixation in acid soils. 1. Identification of the phosphorus fixing soils. Agrono mia Lusitana, Lisboa, 23: 103-116.

Malavolta, E., 1980. Elementos de Nutrição Mineral de Plantas. Ed. Agronōmica Ceres Ltda. São Paulo, 253 p.

MALEINA, A.A., 1958. A method of determining the reserve of available soil phosphates. Soviet Soil Sci, Washington, 4: $450-454$.

MARAIS, P.G., e S.F. FOURIE, 1956. Can we determine the quantity of phosphate available to plants in particular soils? The deciduous fruit grower, Stellenbosch sept., p. 193-196. (popular Article).

MARAIS, P.G.; J. DEIST e C.F.G., HEYNS, 1969. Rejative uptake of fertilizer and soil p by rye plants in pot experiments. Agroplantae. Pretoria, 1: 67-76. 
MATTINGLY, G.E.G., 1957. The use of the isotopes $32 \mathrm{p}$ in recent work on soil and fertilizer phosphorus. Soil and Fertilizers. Bucks, $x x: 59-68$.

MATTINGLY, G.E.G..e 0. TALIBUDEEN, 1960. Isotopic exchange of phosphates in soil. In: Report of the Rothamsted Experimen tal station. Harpenden Herts: 246-265.

MCAULIFFE, C.D.; N.S. HALL; L.A. DEAN E S.B. HENDRICKS, 1948. Exchange reactions between phosphates and soils: hidroxylic surface of soil minerals. Soil Sci. Amer. Proc., Madison, 12: $119-123$.

MEDINA, H.P., 1972. Classificação textural. In:MonıZ,A.C., Coord., Pedologia, São Paulo, Ed. USP, Polígono, p. $21-28$.

MEKHAEL, D.; FATHI AMER; e L. KADRY, 1965. Comparison of isoto pe dilution methods for estimation of plant-availablesoil phosphorus. In: IAEA Isotopes and Radiation in soil-plant, nutrition studies. Viena, $437-448$.

MITCHELL, J., 1957. A review of tracer studies in Saskatchewan on the utilization of phosphates by grain crops. J. Soil Sci, $0 \times$ ford $8: 73-85$.

NELSON, W.L.; B.A. KRANTZ; W.E. COLWELL; W.G. WOLTZ, ARTHUR 
HAWKINS, L.A.; DEAN, A.L. MACKENSIE EE.J. RUBINS, 1948. Application of radioactive tracer technique to studies of phosphatic fertilizer utilization by crops: .1.l. Field experiments. Soil Sci. Soc. Amer. Proc., Madison, 12:113118 .

NEPTUNE, MENARD, L., 1963. Isotope techniques for the determination of phosphorus in soils. Seminar given at the unit of agriculture. IAEA. Viena, mimeografado, 15 .

NEPTUNE, A.M.L., 1964. A técnica do Valor A na determinação do fósforo disponivel do solo e do fertilizante utilizando o arroz (omza sativa L.). Piracicaba, ESALQ/USP, $74 p$. (Tese de Livre docēncia).

NEPTUNE MENARD, L. e A. CAMPANELLI, 1961. Determinação e comparação dos valores $M i, A, Y$, e $S$, em dois tipos de solo do Estado de São Paulo. Anais da ESALQ, Piracicaba, 18: $349-359$

NEPTUNE, A.M.L. e T. MURAOKA, 1978. Uso de isótopos em química e fertilidade do solo-Revisão. R. bras. Ci. Solo, Campinas, 2: $151-163$.

NYE, P.H. eW.N.M. FOSTER, 1958. A study of the mechanism of soil-phosphate uptake in relation to plant species. Plant and Soil. The Hague, ix: 338-352. 
OLSEN, S.R.; F.S. WATANABE e R.E. DANIELSON, 1961. Phosphorus absorption by corn roots as effected by moisture and phosphorus concentration. Soil Sci. Soc. Proc., Madison, 25: $289-294$.

OZBEK, N. e AYDENIZ, 1965. Factors affecting the amount of available soil phosphorus, A-value. In: Isotopes in plant nutrition and physiology. Viena, 35-46.

PATNAIK, S.; S.K. MOHANTY ER.N. DASH, 1979. isotope Technology as applied to studies of soil fertility nutrient availability and fertilizer use on flooded rice soils. In: IAEA Isotopes and Radiation in Research on soil-plant relations hips. Viena, 583-606.

PIMENTEL GOMES, F., 1975. Curso de Estatística Experimental, 7a. ed., São Paulo, Livraria Nobel, 430 .

PONNAMPERUMA, F.N., 1977. The physical-chemical properties of the sumerged soils in relation to fertility. IRRI Research Paper series. Manila, 5: $30 p$.

PROBERT, M.E., 1972. The dependence of isotopically exchangea ble phosphate (L-Value) on phosphate uptake. Plant and Soil. The Hague, $36: 141-148$. 
RENNIE, D.A. e E.D. SPRATT, 1962. Factors affecting and the significance of ' $A$ ' values using band placement. In: IAEA Radioisotopes in soil-plant nutrition studies. Viena, 329342 .

RUSSELL, R.S.; J.B. RICKSON e S.N. ADAMS, 1954. Isotopic equi libria between phosphates in soil and their significance in the assessment of fertility by tracer methods. J. Soil. Sci. $0 \times$ ford, 5: 85-105.

RUSSELL, R.S.; E.W. RUSSELL e P.G. MARAIS, 1957. Factors affecting the ability of plants to absorb phosphate from soils. I. The relationships between labile phosphate and absorption. J. Soil Sci., Oxford, 8: 248-267.

RUSSELL, R.S.; E. W. RUSSELL e P.G. MARAIS, 1958. Factors affecting the ability of plants to absorb phosphate from soils: 11. A comparison of the ability of different specie to absorb labile soil phosphate. J. Soil Sci., Oxford, 9: $101-108$.

RUSSELL, R.S., 1963. Relationship.between the exchange-ability of nutrient ions in the soil and absorption of plants. J. Sci. Food Agric., London, 14: 449-457.

SCHEFFER, F. E B. ULRICH, 1958. Use of 32 for investigations 
in the system: soil/soil, solution/plant. Proc. 2nd., U.N. Int. Conf. on the peaceful uses of atomic energy. Geneva, $27: \quad 149-151$.

SCHENK, M.K. e S.A. BARBER, 1979. Fhosphate uptake by corn as affected by soil characteristics and root morphology. Soill Sci. Soc. Am. J., Madison, 43: 880-883.

SELVARATNAM, V.V.; S. SUMER; A.J. ANDERSEN; J.D. THOMS,EN; GI SEL-NIELSON, G., 1981 . Risoe National Lab. Roskilde. DeMark, Vol. 12, $04,0388-1$.

SHAPIRO, R.E. e W.H. ARMIGER, 1958. Effect of flooding on plant availability of phosphorus from various phosphate Rocks.Agri cultural and Food Chemistry. Beltsville, 6: 453-455.

SOKOLOV, A.V., 1955. Determination of availability of soil phosphates and fertilizers with the aid of radioactive isotopes of phosphorus. In: IAEA. Proc. Un. Int. Conf. Pea ceful uses atomic energy. Geneva, 12: 118-122.

SOKOLOV, A.V., 1958. Supply of available soil phosphates and their accumulation when phosphorus fertilizers are applied. Soviet Soil Sci.. Washington, 2: 117-123.

SPINKS, J.W.T. C S.A. BARBER, 1947. Study of fertilizer 
uptake using radioactive phosphorus: I. Scientific Agriculture. Ottawa, 27: 145-156.

ULRICH, B.; H. LIN E H. KARAPARKAR, 1962. Kinetics of isotopic exchange between soil phosphates, soil solution and plant. In: IAEA Radioisotopes in soil plant nutrition studies. Vie na, $59-74$.

VOLK, V.V. e E.O. MCLEAN, 1963. The fate of applied phospho..rus in four ohio soils. Soil Sci. Soc. Amer. Proc., Madison, $27: 53-58$.

VOSE, P.B., 1980. Introduction to nuclear techniques in agronomy and plant biology, oxford, Pergamon Press, $390 \mathrm{p}$.

WILLIAMS, E.G. e A.H. KNIGHT, 1963. Evaluations of soil phos phate status by pot experiments, conventional extraction methods, and labile phosphate values estimated with the aid of phosphorus-32. J. Sci. Fd. Agric., London, 14:555563.

ZELLER, A., 1963. The feeding power of plants. Seminar given at the unit of agriculture - IAEA. Viena, Mimeografado, $9 p$. 
APENDICE 


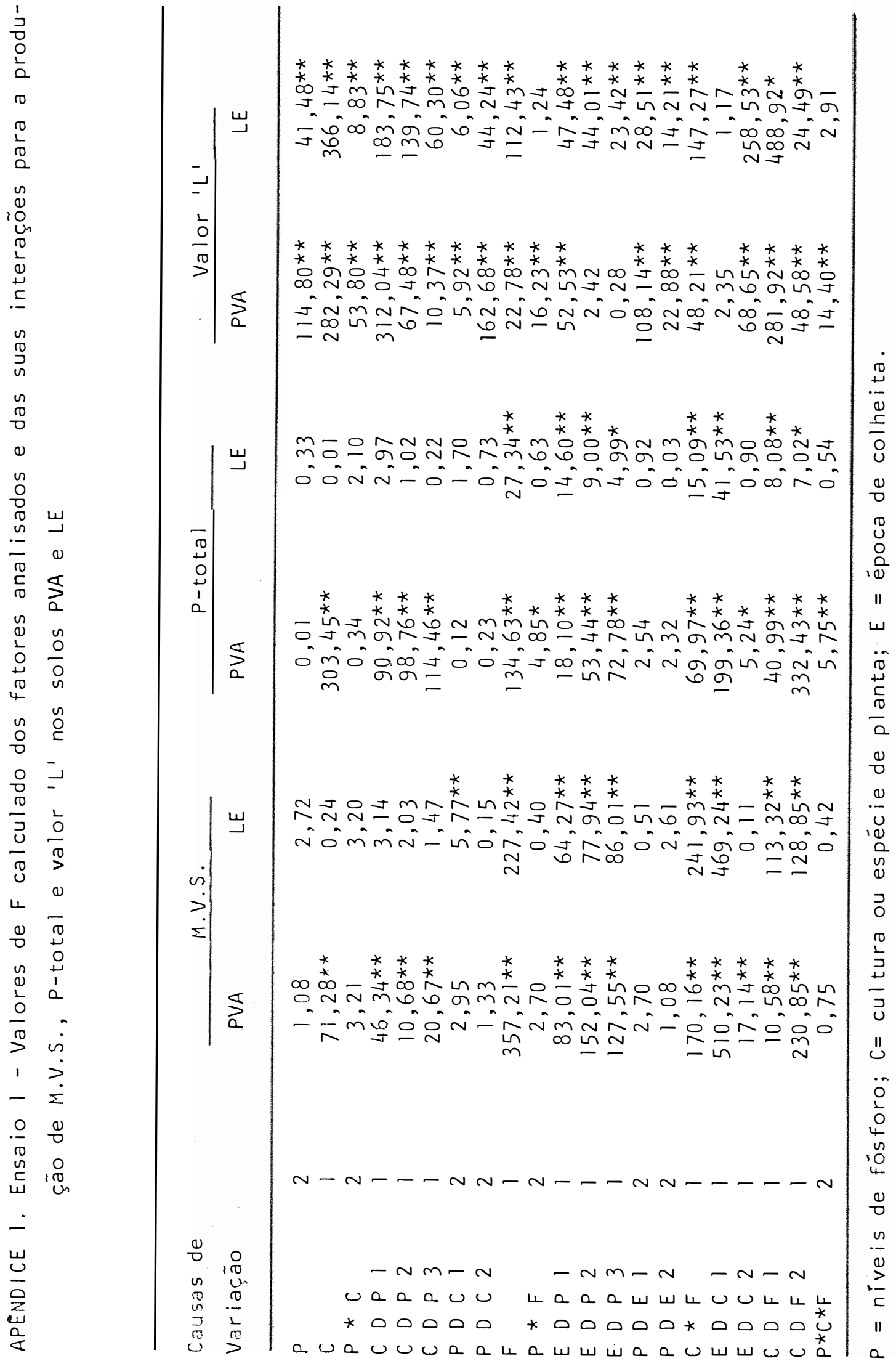




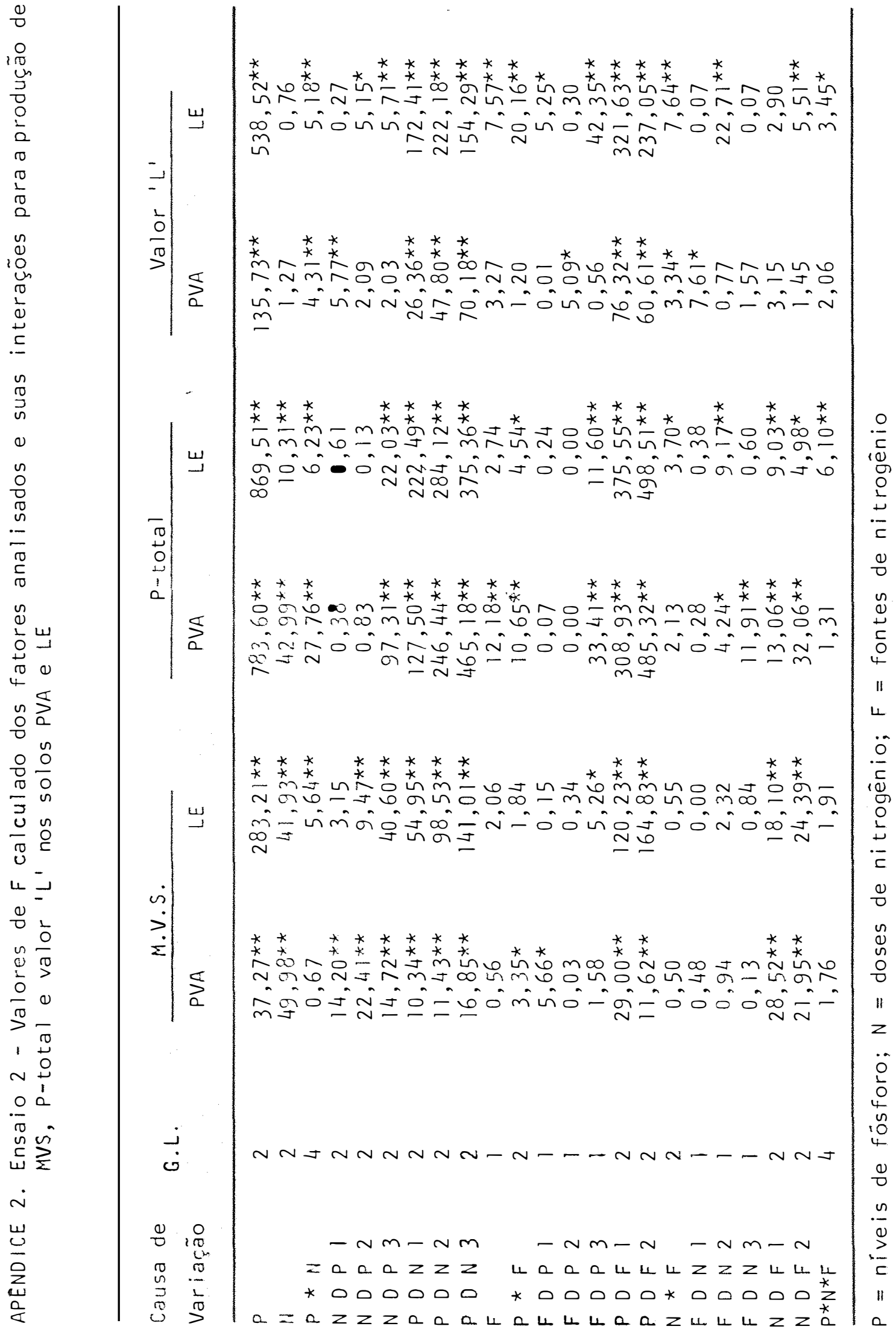


APENDICE 3. Ensaio 4 - Valores de F calculado dos fatores analisados e das suas interações para a produção de MVS, P-total e valor 'L':a) nas duas culturas; b) nas duas condições de cultivo

a)

\begin{tabular}{|c|c|c|c|c|}
\hline $\begin{array}{l}\text { Causas de } \\
\text { Variação }\end{array}$ & G.L. & M.V.S. & P-total & Valor 'L' \\
\hline$P$ & 2 & $28,03 * \star$ & $33,48 * \star$ & $45,69 * *$ \\
\hline c & 1 & $48,44 \star \star$ & $208,53 * \star$ & $365,94 * \pi$ \\
\hline$P * C$ & 2 & $5,54 *$ & $10,75^{\star \star}$ & $3,64 \star$ \\
\hline CDP 1 & 1 & 3,40 & $34,53 * \star$ & $167,24 * \star$ \\
\hline CDP 2 & 1 & $13,61 * \star$ & $50,06 * *$ & $83,11 * \star$ \\
\hline $\operatorname{CDP} 3$ & 1 & $42,52 \star \star$ & $145,43 * \star$ & $122,87 * \star$ \\
\hline PDC 1 & 2 & $28,86 * \star$ & $40,34 * *$ & $13,71 * \star$ \\
\hline PDC 2 & 2 & $4,72^{\star}$ & $3,89 *$ & $35,61 * *$ \\
\hline S & 1 & $73,10 * \star$ & $63,32 * \star$ & $580,41 * *$ \\
\hline$P * S$ & 2 & 0,55 & $4,46 *$ & $21,10 \star \star$ \\
\hline SDP I & 1 & $23,60 * \star$ & $12,71 * \star$ & $371,63 * *$ \\
\hline SDP 2 & 1 & $17,93 * \star$ & $10,18 * \star$ & $132,85^{\star \star}$ \\
\hline SDP 3 & i & $32,66 * \star$ & $49,36 * \star$ & $119,33 * *$ \\
\hline PDS 1 & 2 & $12,47 \star \star$ & $29,37 \star \star$ & 2,24 \\
\hline PDS 2 & 2 & $16,11 \star \star$ & $8,57 \star \star$ & $65,15 * \star$ \\
\hline$C * S$ & $i$ & $43,75^{*} \star$ & $117,86 * \star$ & $199,40 * \star$ \\
\hline SDC I & 1 & 1,87 & $176,99 * *$ & $49,70 * \star$ \\
\hline SDC 2 & $i$ & $114,98 * \star$ & 4,20 & $730,11 * \star$ \\
\hline CDS 1 & 1 & $92,13 * \star$ & $319,98 * \star$ & $12,54 * \star$ \\
\hline $\operatorname{CDS} 2$ & 1 & 0.05 & $6,42 \star$ & $552,81 * *$ \\
\hline$P * C * S$ & 2 & $7,31 * \star$ & 0,20 & 1,61 \\
\hline
\end{tabular}

\begin{tabular}{|c|c|c|c|c|}
\hline \multicolumn{5}{|l|}{ b) } \\
\hline$P$ & 2 & $34,24 * \star$ & $25,88 * \star$ & $54,15 * \star$ \\
\hline$S$ & 1 & $237,28 * \star$ & $241,23 * \star$ & $673,69 * \star$ \\
\hline$p * s$ & 2 & $3,56 \star$ & 1,78 & $8,09 * \star$ \\
\hline SDP 1 & 1 & $50,34 * *$ & $64,79 * \star$ & $197,37 * \star$ \\
\hline SDP 2 & 1 & $117,91 * \star$ & $79,73 * \star$ & $161,96 * *$ \\
\hline SDP 3 & 1 & $76,14 * \star$ & $110,28 * \star$ & $330,54 * \pi$ \\
\hline PDS 1 & 2 & $24,47 \star \star$ & $20,33 * \star$ & $31,70 * \star$ \\
\hline PDS 2 & 2 & $13,33 * \star$ & $7,33^{* *}$ & $30,54 * \star$ \\
\hline U & 1 & $276,38 * \star$ & $146,27 * \star$ & $39,66 * \star$ \\
\hline$P \star U$ & 2 & 2,43 & 0,51 & $3,63 *$ \\
\hline UDP 1 & 1 & $125,01 * \star$ & $50,14 * \star$ & 3,30 \\
\hline UDP 2 & 1 & $65,01 * \star$ & $58,48 * \star$ & $12,04 * \star$ \\
\hline UDP 3 & 1 & $91,21 \star \star$ & $38,67 * \star$ & $31,57 \star \star$ \\
\hline PDU 1 & 2 & $12,94 * \star$ & $10,69 * \star$ & $19,74 * \star$ \\
\hline PDU 2 & 2 & $23,73 \star \star$ & $15,70 * \star$ & $38,04 * \star$ \\
\hline$S * U$ & 1 & $11,02^{\star \star}$ & $8,77^{\star \star}$ & $28,55 \star \star$ \\
\hline UDS 1 & 1 & $88,49 * *$ & $41,69 * *$ & 0,45 \\
\hline UDS 2 & 1 & $198,91 * *$ & $113,36 * *$ & $67,76 * \star$ \\
\hline SDU 1 & 1 & $73,00 * *$ & $78,98 * *$ & $489,82 \star \star$ \\
\hline SDU 2 & 1 & $175,31 * \star$ & $171,03 * \star$ & $212,42 * \star$ \\
\hline$p \star c * U$ & 2 & 0,88 & 1,70 & $8,75^{\star \star}$ \\
\hline
\end{tabular}




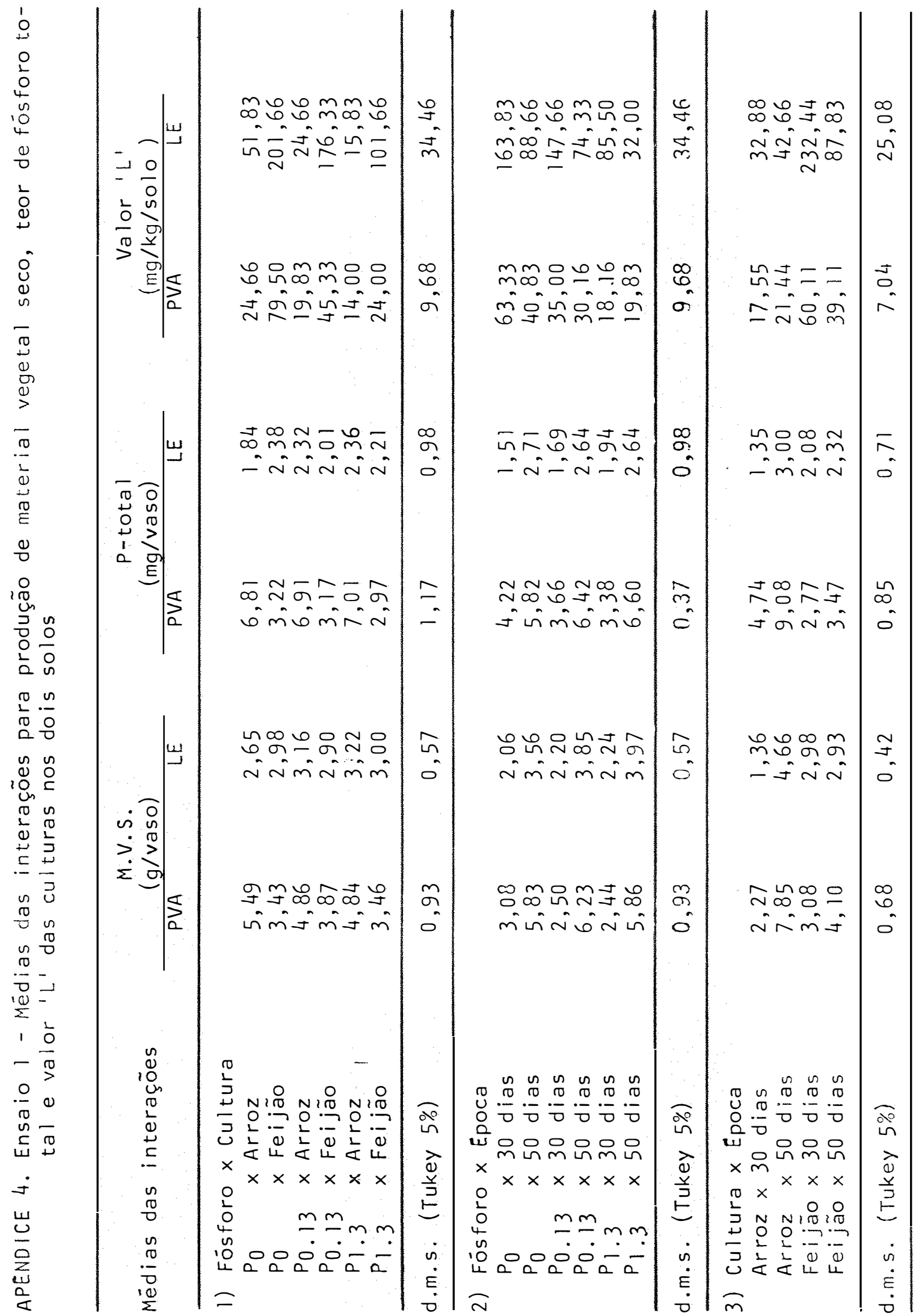




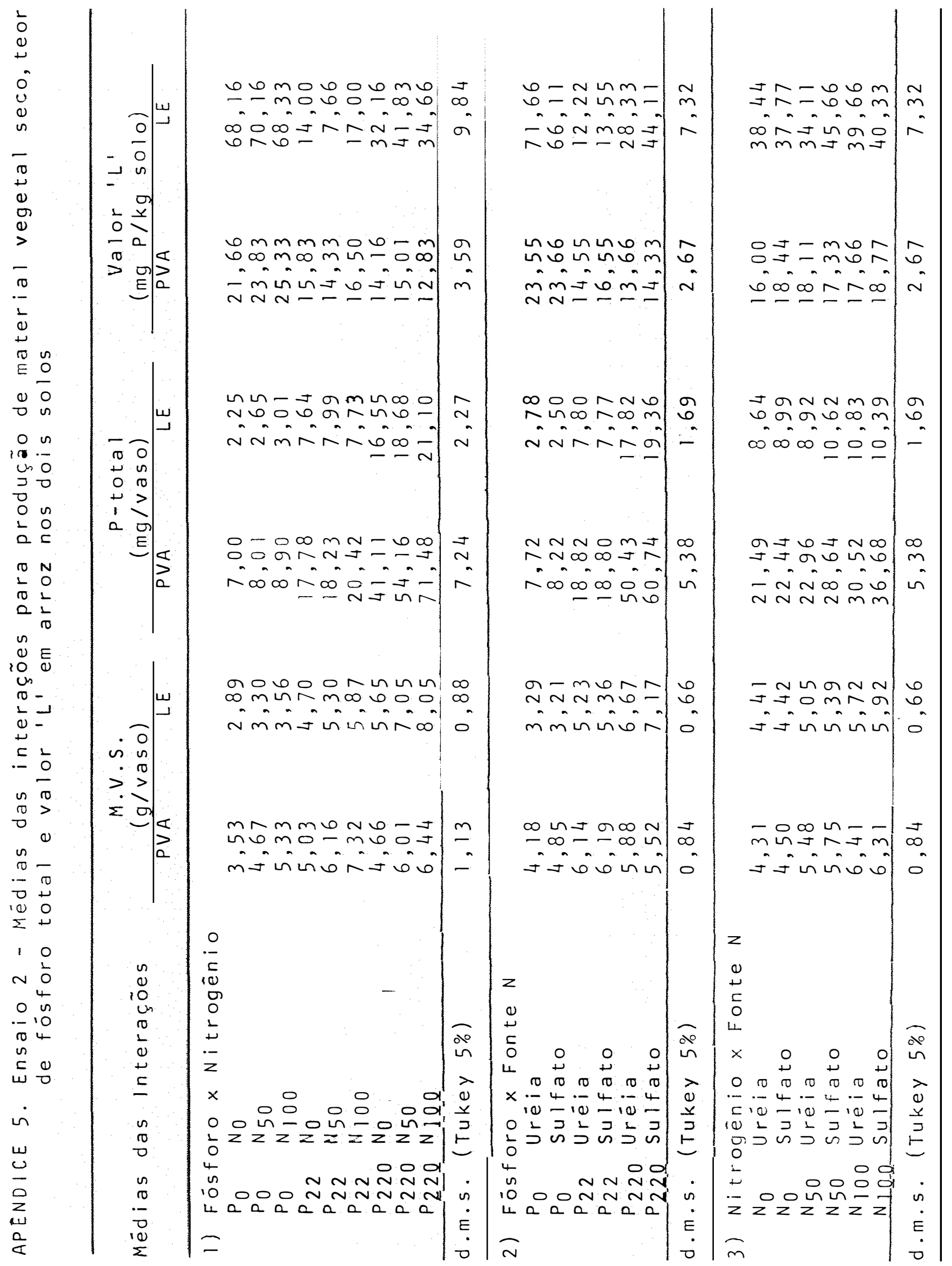

